\title{
Kant's dynamical theory of matter in 1755 , and its debt to speculative Newtonian experimentalism
}

\author{
Michela Massimi \\ Dept. of Science and Technology Studies \\ University College London
}

\begin{abstract}
This paper explores the scientific sources behind Kant's early dynamical theory of matter in 1755, with a focus on two main Kant's writings: Universal Natural History and Theory of the Heavens and On Fire. The year 1755 has often been portrayed by Kantian scholars as a turning point in the intellectual career of the young Kant, with his much debated conversion to Newton. Via a careful analysis of some salient themes in the two aforementioned works, and a reconstruction of the scientific sources behind them, this paper shows Kant's debt to an often overlooked scientific tradition, i.e. speculative Newtonian experimentalism. The paper argues that more than the Principia, it was the speculative experimentalism that goes from Newton's Opticks to Herman Boerhaave's Elementa chemiae via Stephen Hales' Vegetable Staticks that played a central role in the elaboration of Kant's early dynamical theory of matter in 1755.
\end{abstract}

Keywords: Kant, repulsive force, air, ether, Newton, Hales, Boerhaave

\section{Introduction}

In 1786, in Metaphysical Foundations of Natural Science, Kant famously introduced attraction and repulsion as two fundamental forces in nature, within the context of his defence of a "dynamical natural philosophy". The purpose of a "dynamical natural philosophy" was to explain natural phenomena in terms of "moving forces of attraction and repulsion originally inherent in them", ${ }^{1}$ by contrast

\footnotetext{
${ }^{1}$ AK 4: 532.38 - 533.1. Kant (1786); English translation (2004), p. 72. In this context, Kant uses the terms Anziehung und Zurückstoßung to indicate, respectively, attractive and repulsive force as forces inherent in matter, and responsible for matter's different specific densities. Both forces act among parts of matter. Indeed, at the outset of the chapter on Dynamics (Explication 2), Kant says that there are only these two forces (Anziehung und Zurückstoßung) with which one point of matter can impress
} 
with the "mechanical natural philosophy" which "under the name of atomism or the corpuscular philosophy" retained its authority and influence from Democritus to Descartes. Repulsive force was introduced to explain how matter can fill a determinate region of space: it was regarded as an expansive force "also called elasticity" and "all matter is therefore originally elastic". ${ }^{2}$ To illustrate repulsive force as an original elastic force that comes in degrees in different matters, Kant repeatedly resorted to the example of air, or "air matters", ${ }^{3}$ sometimes associated with heat ${ }^{4}$ intended either as "oscillation of elastic matter" ${ }^{5}$ or (in the General Remark to Dynamics) as the "matter of heat...whose own elasticity is perhaps original". 6 A few lines below in the same passage, Kant called the matter of heat "caloric", [Wärmestoff] and presented it as an example of chemical penetration, insofar as it penetrates the empty interstices of bodies. Kant gave also other examples of chemical penetration, namely the dissolution of matter as when acids dissolve metallic bodies

motion on another (AK 4: 498.17-33). A few lines down, in Proposition 2 [AK 4: 499.6-18, 500.2] and throughout the chapter, Kant uses Zurückstoßungskraft interchangeably with repulsive Kraft, and he explicitly identifies it with an expansive force (Ausdehnungskraft or expansive Kraft), which is nothing but the elasticity of matter (Elasticität).

Apropos of attraction, Edwards (2000), p. 142, identifies in the chapter on Dynamics (but also in Universal Natural History) two possible views of it, which he calls a "collective view", identifiable with Newtonian gravitation (Gravitation) as a long-range force acting at a distance on planetary bodies, and a "distributive view", identifiable with the cohesion of solid bodies as a short-range force (Anziehung) acting by contact between juxtaposed parts of matter. One may wonder whether a similar distinction can be found in the same period as far as repulsive force is concerned (for example, the repulsive force at work between the north and south poles of two magnets when brought together seems to defy the characterization of Zurückstoßungskraft as a short-range contact force-I thank an anonymous referee for pointing this out). It suffices here to note that - as we will see below-the terminology Anziehung und Zurückstoßung as used in the aforementioned passage from the 1786 chapter on Dynamics is exactly the same terminology Kant used thirty years earlier in the 1755 Universal Natural History, where he first presented his dynamical theory of matter.

${ }^{2}$ AK 4: 500.2-6.

${ }^{3}$ AK 4: 500.20-26. English translation, p. 37: "When, in the barrel of an air pump filled with air, the piston is driven closer and closer to the bottom, the air-matter [Luftmaterie] is compressed. If this compression could now be driven so far that the piston completely touched the bottom...then the airmatter would be penetrated". And again, AK 4: 505.10 - 19, English translation p. 42: "the smallest parts of the air repel one another in inverse ratio to their distances from one another, because the elasticity of these parts stands in inverse ratio to the spaces in which they are compressed.... gareater or smaller space is to be represented as completely filled by one and the same quantity of matter, that is, one and the same quantum of repulsive force".

${ }^{4}$ AK: 4: 522.30-38, English translation p. 61: "But we may also view the expansive force of air not as the action of originally repelling forces, but as resting rather on heat, which compels the proper parts of air...to flee one another, not merely as a matter penetrating it, but rather, to all appearances, through its vibrations". And again AK 4:524.02-06, English translation p. 62: "attraction rests on the aggregate of matter in a given space, whereas its expansive force, by contrast, rests on the degree of filling of this space, which can be very different specifically (as the same quantity of air, say, in the same volume, manifests more or less elasticity in accordance with its greater or lesser heating)".

${ }^{5}$ AK 4:522.37. Eng. trans. p. 61.

${ }^{6}$ AK 4:530.2-3. Eng. trans. p. 69.

${ }^{7}$ AK 4:532.4. 
or the "dissolving forces" at work in "vegetable or animal operations". ${ }^{8}$ There follows Kant's defence of the ether as a matter filling all space, but very subtle compared to the matter of ordinary bodies: "In the aether, the repulsive force must be thought as incomparably larger in proportion to its inherent attractive force than in any other matters known to us".

Why does Kant say that repulsive force, as an expansive elastic force comes in different degrees in different matters, among which nonetheless the same attractive force operates? ${ }^{10}$ Why does he refer to the expansive force of air, heat, and ether to illustrate the different degrees of repulsive force at work in nature? What do air, heat, and ether have in common that justifies their association with repulsive force? In this paper, I take a first step towards answering these open questions.

Thirty years earlier, in the 1756 Physical Monadology, Kant had already introduced some seminal ideas for his dynamical theory of matter. Not only did he introduce the two fundamental forces of attraction and repulsion; but he also expressly made repulsive force the cause of the impenetrability of bodies, and identified it with an elastic force acting by direct contact, and coming in different degrees in different things (hence the different elasticities of bodies). ${ }^{11}$ And among elastic bodies, Kant included the "aether, that is to say, the matter of fire". 12

I believe that some pre-Critical aspects of Kant's dynamical theory of matter were taken up in more complex ways in the Critical period, so I do not want to make any swift claim suggesting that we should read the Metaphysical Foundations through the lenses of the pre-Critical writings of 1755-6. However, I do think that some baffling aspects of Kant's Critical treatment of repulsive force have their seeds in the pre-Critical theory of matter of 1755. It is the aim of this paper to shed light on them

\footnotetext{
${ }^{8}$ AK 4:531.39. Eng. trans. p. 71.

${ }^{9}$ AK 4: 534.9-11. English translation, p. 73

${ }^{10}$ AK 4:533.38 - 40, 534.1-2. English translation, p. 73: "repulsive force, which has a degree that can be different in different matters; and, since in itself it has nothing in common with the attractive force, which depends on the quantity of matter, it may be originally different in degree in different matters whose attractive force is the same".

${ }^{11}$ AK 1: 483.11, 486.36-38. Kant explained in Proposition XII how the different densities of bodies in the nature ("for example, aether, air, water, and gold") should be explained by assuming "a specific difference between the simplest elements" that compose bodies (AK 1: 486.11-13). In the following Proposition XIII he then ascribed to individual simple elements an innate, perfectly elastic force "which is different in different things" and through which the elements would occupy the space of their presence (AK 1: 486.36-38, 487.1-2).

${ }^{12}$ AK 1: 487.18. Kant (1756), English translation (1992), p. 66. As we shall see below, the introduction of attraction and repulsion, and the identification of the ether as the repository of repulsive force and as the matter of fire pre-dates Physical Monadology, appearing for the first time in 1755 in De igne.
} 
by reconstructing some of the scientific sources behind Kant's identification of repulsive force with an expansive, elastic force acting by contact.

I am going to concentrate on the very origins of Kant's dynamical theory of matter in Universal Natural History and Theory of the Heavens (1755a), and De igne (1755b-henceforth referred to as On Fire). I identify an important, and so far overlooked, scientific tradition behind it, namely British and Dutch natural philosophy of the eighteenth century, which — with a firm footing in the Queries of Newton's Opticks (first Latin edition 1706; second English edition 1717)_flourished in England with Stephen Hales' Vegetable Staticks (1727) and in Leiden with Herman Boerhaave's Elementa chemiae (1732). The relevance of this alternative experimental tradition can be found not only in Kant's analysis of repulsive force in the explanation of a variety of chemical and thermal phenomena in On Fire, but also in some key aspects of his cosmogony (1755a) as well as in his early elaboration of causality in New Elucidation (1755c), as I shall mention in Section 3.2.

While most of the secondary literature on this topic has in recent times concentrated on Kant's conversion and debt to Newton's Principia, especially as far as his 1786 defence of Newton's universal gravitation is concerned, ${ }^{13}$ some scholars have drawn attention to the relevance of corpuscular and chemical theories of matter in the seventeenth and eighteenth century natural philosophy for Kant's dynamical theory of matter. ${ }^{14}$ The aim of this paper is to contribute to the existing literature by both (i) complementing the received view of Kant's debt to the Principia, on the one hand, and (ii) by further exploring the legacy of both dynamical corpuscularism and materialism of the seventeenth century for Kant's early theory of matter, on the other hand.

The paper is divided in five sections. In Section 2, I focus on some salient aspects of Kant's Universal Natural History that in my view betray his allegiance to

\footnotetext{
${ }^{13}$ See especially Friedman (1992a), (1992b), (2004) translation of Kant (1786), and (2006). For a detailed reconstruction of Kant's conversion to Newton in the pre-Critical writings after 1747, see Schönfeld (2000). For Kant's early dynamics (with a particular focus on Kant's first 1747 work True estimation of living forces and on Kant's 1755 cosmogony), see also Schönfeld (2006a) and (2006b), respectively.

${ }^{14}$ See Adickes (1924); Carrier (1990), (2001); Edwards (2000), chapter 6. Edwards, in particular, has argued that the assumption of physical ether, as an imponderable elastic matter, is pivotal to Kant's dynamical theory of matter, and more in general to the evolution of Kant's thought from the preCritical writings of 1755 through the Critical period, up to the Opus postumum. It is not the aim of this paper to draw any overarching conclusion about the role of Kant's dynamical theory of matter for his overall philosophical project. My more modest aim is to clarify what I take to be some relevant scientific sources for understanding better Kant's treatment of repulsive force.
} 
the more speculative Newton of the Opticks. To substantiate these claims, in Section 3 , I give a rather detailed survey of some aspects of speculative Newtonianism ( $§ 3.1)$, as these aspects were further developed by Stephen Hales (to whom $\S 3.2$ is dedicated) and by Herman Boerhaave ( $§ 3.3$ ). My interpretive line is that Newton's ambiguity about the ether engendered two traditions, a mechanical one and a materialistic one-to borrow Schofield's (1970) terminology-which can be respectively found in Hales' experiments on elastic airs, and Boerhaave's theory of fire; and that these two traditions got intertwined in Kant's dynamical theory of matter in 1755.

More precisely, (a.) the Newton of pre-Principia and Opticks offered air first, and the ether then as the repository of repulsive force; (b.) Stephen Hales' 'chymiostatical experiments' on airs, building on Newton, provided the main source of inspiration for Kant's repulsive force manifesting itself in the dissolution of matter in vapours as per Universal Natural History; (c.) the chemical role of Hales' elastic air influenced in turn Herman Boerhaave's theory of fire as a material substance trapped in all bodies and released in combustions. This, in turn, provided the main source of inspiration for Kant's On Fire (Section 4), whereby Kant operated a synthesis between Newton's ether as the matter of light and Boerhaave's matter of fire (in surprising continuity with the much later role of the ether of the Opus postumum as Wärmestoff). ${ }^{15}$ In Section 5, I draw some concluding remarks about the nature of Kant's debt to Newtonianianism.

\section{Universal Natural History and Theory of the Heavens}

Universal Natural History is certainly one of the most important Kantian texts of the pre-Critical period. In it, Kant advanced the hypothesis of the origin of the universe from a nebula, in which attractive and repulsive forces were at work. Kantian

\footnotetext{
${ }^{15}$ In the Opus postumum, in the ix fascicle "Towards an elementary system of the moving forces of matter", Kant introduced the ether as an "originally elastic matter" acting both as the matter of light and the matter of heat or "caloric (...) regardless of the fact that, in the latter condition, it is neither a fluid nor repulsive, but only makes fluid and expand their matter" AK 22: 214.13-22. Kant (1936, 1938); English translation (1993), p. 33. The link between ether and repulsive force becomes explicit in a note on the left margin of sheet I of ix fascicle, where Kant says: "Repulsion can act as a superficial force, or as a penetrative force (but not one acting at a distance, like gravitation). In the latter case, the repulsion of all internal material parts of all bodies is heat. One could call the ether empyreal air (...) as an expansive matter whose penetration contains the ground of all the forms of air" AK 22: 214.23-27, 215.2. English translation, p. 33. Note that here too Kant uses the term Zurückstoßung to denote repulsive force as a superficial force (Flächenkraft) or a penetrative one (durchdringende Kraft), in either case as a force acting by direct contact and not at a distance by contrast with Newton's universal gravitation, denoted here by the term Gravitation (not Anziehung).
} 
scholars have been unanimous in reading this 1755 text as the manifesto of Kant's conversion to Newton, after the 1747 work True estimation of living forces dominated, as it were, by the ongoing debate between Leibnizians and Cartesians. ${ }^{16}$ The purpose of my paper is to clarify some aspects of Kant's much celebrated conversion to Newton. Kant's dynamical theory of matter has been for long time associated with Newton's Principia. The association is justified and supported by the Metaphysical Foundations of Natural Science (abbreviated here as MAN), where attraction is identified as a force acting at a distance through empty space. ${ }^{17}$ But Kant's treatment of repulsive force raises some issues that in my view betray a more complex story than unqualified adherence to the Principia. If we look at the history of Kant's own ideas, and how thirty years earlier he came to elaborate his embryonic dynamical theory of matter in Universal Natural History and On Fire, we can see some of the seeds of his mature dynamics and get a more nuanced picture of his conversion to Newtonianism. I am going to argue in this paper that it was Newton's speculative experimentalism more than his mechanics that provided the source of inspiration for Kant's treatment of repulsive force in the early dynamical theory of matter. And this would clarify some of the prima facie puzzling aspects of it (for example, why is it a contact force, by contrast with attraction? Why is it identified with an elastic, expansive force coming in different degrees in different materials?)

I do not mean to deny the importance of the Principia for Kant's adoption of attraction as a universal driving power of nature. But I think that while much attention has been paid to this particular aspect of Kant's philosophy of nature, not enough attention has been paid so far to Kant's more puzzling characterization of repulsive force, which - if my interpretive line here below is correct - betrays his allegiance to the Newton of the Queries of Opticks more than to the Principia. Moreover, and incidentally, I think that Kant's analysis in Universal Natural History of the mechanism responsible for the formation of celestial bodies via the interaction of attraction and repulsion betrays once more Kant's idiosyncratic take on Newton. Kant did not lay out an explicit set of mechanical laws in Universal Natural History and the dynamical mechanism he envisaged to explain how planets formed and began to spin in terms of attraction and repulsion cannot, of course, be found in Newton's Principia,

\footnotetext{
${ }^{16}$ On the relevance of Universal Natural History for Kant's conversion to Newton, see for example Schönfeld (2000), pp. 89-95; Friedman's Introduction to the (2004) translation of Kant (1786), and Introduction to (1992a).

${ }^{17}$ AK 4: $512.18-19$.
} 
since Newton did not provide a cosmogony. Yet Kant's subtitle reads "An essay on the constitution and mechanical origin of the whole universe treated according to Newton's principles". Scholars have read this as a sign of Kant's endorsement of Newton's Principia, but I contend that Kant's cosmogony is in fact at odds with Newtonian principles in some relevant aspects. ${ }^{18}$ The mechanism involving attraction and repulsion that Kant envisaged in Universal Natural History shows signs of divergence from Newton's Principia (§ 2.1). ${ }^{19}$ Moreover, Kant's repulsive force is borrowed from Newton's theory of matter as exposed in some pre-Principia works and in the Opticks, rather than from Newton's mechanics of the Principia (as I am going to show in $\S 2.2$ ). Thus, investigating Kant's early dynamical theory of matter in 1755 can help us get a more nuanced picture of his much celebrated conversion to Newton.

\subsection{In what respects Universal Natural History shows signs of divergence from} Newton's Principia

Kant's cosmogony is based on the idea of subtle particles of matter being originally diffused across celestial space. Kant did not expressly speak of ether in Universal Natural History; instead in continuity with both the 1747 essay True estimation of living forces, and the 1754 essay on the Earth's axial rotation, he talked of a "fine stuff" diffused in celestial space. ${ }^{20}$ Already in the 1747 essay, Kant had introduced the assumption of an "infinitely subtle space" in the context of a discussion of Leibniz's vis viva to explain how the motion of bodies through space may result in different actions / effects (Wirkungen) on the basis of their interaction with the "little molecules of space". ${ }^{21}$ He seemed to believe that for

\footnotetext{
${ }^{18}$ I thank Eric Watkins, Robby Gustin, and an anonymous referee for comments that helped me refine this point.

${ }^{19}$ One may retort that since the Principia does not provide a cosmogony, it is not surprising after all that Kant's Universal Natural History is at odds with it. Of course, it was not the aim of the Principia to explain how planets formed or began to spin. The issue though remains as to why Kant's subtitle reads "An essay on the constitution and mechanical origin of the whole universe treated according to Newton's principles". What are the "Newton's principles" Kant referred to here, since there is no mention of either Newton's three laws or the law of universal gravitation? Could they be tracked down in the Principia? The following sub-section (2.1) should be read with an eye towards answering these questions.

20 "feinen Grundstoffe" AK 1: 268.20. Kant (1755a), English translation (1969), p. 69.

21 "unendlich subtilen Raume" and "kleine Moleculas des Raumes" AK 1: 29.8, 29.24. Kant (1747),

English translation (in press), p. 39. I thank Eric Watkins to allow me access to a pre-print version of the English translation.
} 
motion of freely moving bodies to obey Leibniz's law of squared velocity, it was necessary to assume that space was not empty but filled with "an infinitely rarified matter, which has accordingly infinitely little resistance". ${ }^{22}$ The idea of a spatial plenum in this context came indeed from Leibniz's fluid vortex theory offering little resistance to the motion of bodies, and Kant seemed to take it as part and parcel of Leibniz's theory. ${ }^{23}$

While the 1747 essay was still very much rooted in the tradition of Leibniz's metaphysical dynamics, the first signs of Kant's adherence to Newtonian physics appeared in the 1754 essay on the Earth's axial rotation, whereby Kant seemed to take the distance from Leibniz's fluid vortex theory and replaced it with the idea of a more subtle and "infinitely less resisting" matter filling celestial space, which would allow "a free unhindered motion to the light vapour of comets", as Newton had shown. ${ }^{24}$ Here Kant ascribed directly to Newton the hypothesis of a very subtle and infinitely less resisting matter filling the cosmic space, the very same type of matter that he assumed to fill the cosmos a year later, in Universal Natural History. But what was this subtle matter offering infinitely weak resistance to the motion of comets and celestial bodies? As we shall see in Section 3, there was a natural candidate for this

\footnotetext{
22 "den Raum...mit Materie, aber mit unendlich dünner, folglich unendlich wenig widerstehender Materie erfüllt" AK 1: 115.7-9. English translation (in press), p. 145. In the case of two bodies with the same mass and traversing the same space (with different velocities), the one with greater velocity would have a greater effect on the account of the number of particles in space, to which it would have imparted a greater velocity, according to Kant's argument.

${ }^{23}$ See Leibniz's (1689) “Tentamen de motuum coelestium causis", written after seeing the review of Newton's Principia in Acta eruditorum. Leibniz formulated a theory of gravity that could provide a mechanical explanation for it via the fluid vortex. Like Huygens in Horologium Oscillatorium (1673), Leibniz too explained orbital motions as the result of two opposite forces: gravity and what Huygens called the 'centrifugal force', i.e. the force to recede from the centre. Huygens had explained gravity as a force opposite to the centrifugal one, which in turns originated from a subtle fluid surrounding the body. As Bertoloni Meli (1993), ch. 2, has persuasively argued, after the appearance of Newton's Principia, Huygens re-interpreted the subtle fluid as an ether consisting of very light particles - so light that they could not impede the motion of planets and comets through the ether-and whose varying density could explain the varying velocities of rotation of planets. Huygens' idea that gravity could be explained as a force opposite to the centrifugal one inspired Leibniz, who had independently been studying the link between gravity and what he called 'elasticity' from the early 1670s, following up the tradition of Robert Boyle as well as the other important tradition of mechanical studies on elastic impact by Huygens himself and Mariotte. This latter tradition of studies on elastic impact bore direct links with Leibniz's studies on vis viva, which Kant profusely discussed in ch. 2 of his 1747 True estimation. The ability of an elastic body to squeeze and return back to its original shape was regarded as the expression of the body conserving his force in the Specimen dynamicum and other Leibnizian writings of the period. In his mature years, Leibniz explained elasticity in mechanical terms, i.e. in terms of subtle fluids, and he took it to be a fundamental property of matter in the universe, or better, as Bertoloni Meli calls it, a "structural principle of matter".

24 “der Himmelsraum...mit unendlich wenig widerstehender Materie erfüllt sei” AK 1: 186.30-33. Kant (1754), English translation (1968), p. 159.
} 
role within Newton's natural philosophy: namely, the ether, which although did not appear in the first edition of Newton's Principia (1687), it featured nonetheless in the second edition (1713), thanks to the enormous resonance that the first Latin (1706) edition of the Opticks had had in the meantime, with a new set of Queries where the ether featured. $^{25}$ So, when in 1755 Kant referred to a feinen Grundstoffe diffused in the primordial cosmic space, he was building upon an ongoing controversy between Leibniz's fluid vortex theory and Newton's infinitely weakly resisting ether.

Yet Kant's somewhat nuanced approach to "Newtonian principles" becomes evident if we consider the mechanism envisaged for the formation of celestial bodies out of the subtle matter diffused through space. Despite attraction lumping the primordial fine matter to form planets and stars, attraction per se was not sufficient to explain the origin of heavenly bodies. It was the combination of Newtonian attraction and of what Kant called "the mechanical consequences of the general laws of resistance" 26 that explained the formation of heavenly bodies out of whirling primordial matter. The other force responsible for the formation of heavenly bodies was indeed the repulsive force, ${ }^{27}$ whose main role-according to Kant-was to counterbalance the attractive force, and make the fine matter whirl in vortices.

While attraction was deemed responsible for the formation of increasingly bigger lumps of matter, which eventually resulted in planets and stars, repulsion was entrusted with the crucial role of explaining how the particles of matter-instead of collapsing into one big lump - began to whirl in vortices of different densities that eventually resulted in the different planets and stars that we observe.

Kant ascribed to the inter-particulate repulsive force the role of turning sideways the particles of primordial matter from their rectilinear motions (due to attraction): "Their perpendicular fall thereby issues in circular movements, which encompass the

\footnotetext{
${ }^{25}$ Westfall (1971) ventures an explanation for the revival of the ether in the second edition of the Principia and, most importantly, in the Opticks: "[Newton] introduced the aether to provide a mechanical explanation of forces which had appeared so occult to a generation raised on the mechanical philosophy" p. 395. But by contrast with Descartes' dense material ether or Leibniz's fluid one, Newton's ether was supposed to be very subtle and offering almost no resistance to the motion of celestial bodies. Aiton (1972), ch. 6, refers to two manuscripts of Newton around 1714, following the second edition of Principia ('Ex epistola cujusdam ad amicum' and 'Notae in Acta eruditorum an.89 p. 84') where Newton discussed the specific problem of comets against Leibniz's fluid vortex theory, while Bertoloni Meli (1993), p. 199, quotes a letter of Newton to Leibniz on 17 March 1693, where Newton defended empty space and challenged Leibniz to explain how planets and comets may travel unhindered through the etherial fluid.

${ }^{26}$ AK 1: 267.16. Kant (1755a), English translation (1968), p. 67.

${ }^{27}$ Again, the terminology used is Anziehung and Zurückstoßungskraft.
} 
centre towards which they were falling". ${ }^{28}$ And once the central body had grown enough to attract an increasing number of particles to it, under the effect of repulsion among them, lateral movements took place producing "whirls or vortices of particles, each of which by itself describes a curved line by the composition of the attracting force and the force of revolution that has been bent sideways". ${ }^{29}$ Thus, the free circular movements of primordial particles were the products of the two fundamental forces of attraction and repulsion, as "essential forces" 30 of matter, whose counterbalance ensued the vortex mechanism, key to Kant's cosmogony.

This mechanical explanation of the formation of particle vortices - due to interparticulate repulsion - was not to be found in the Greek atomists, from Epicurus to Democritus, with their "absurd fancies regarding the cause and consequences of [particles' deviation from straight line]". ${ }^{31}$ Nor was to be found in Descartes' vortex theory either. But, interestingly enough, it was not to be found in Newton's Principia either. While Newton had introduced attraction and repulsion already in the first edition of Principia, he did not envisage for them the type of counterbalance and role that Kant bestowed on them for his cosmogony. ${ }^{32}$ For Newton, the centrifugal force was a force equal and opposite the centripetal force, as per Newton's III law, without any further grounding into attraction and repulsion. For Kant, on the other hand, centripetal and centrifugal forces at work in planetary motions had to be given a dynamical grounding in terms of attractive and repulsive forces acting among the particles of the primordial matter. Moreover, Kant introduced Newtonian attraction as a force inherent in the primordial matter, or as an "essential force" of matter, in contrast with Newton, who resisted the accusation of his foes (from Leibniz to Berkeley) that attraction was an "essential force" of matter, and hence possibly an occult quality. ${ }^{33}$ In this way, Kant's cosmogony could dispense with what he took to be Newton's 'God of the working days'. In Kant's hands, Newtonian attraction became immanent the fine matter and via a mechanical mode, it became one of the causal agents responsible for the constitution of the universe.

Kant's guarded attitude towards Newton's mechanical laws becomes even more evident in the Second Part, First Chapter. Kant took the lead from Maupertuis'

\footnotetext{
${ }^{28}$ AK 1: 265.6-8. Kant (1755a), English translation (1968), p. 64.

29 "Wirbel von Theilchen". AK 1: 265.30-32. English translation, p. 65.

30 "wesentliche Kräfte" AK 1: 264.21.

${ }^{31}$ AK 1: 226.36. English translation, p. 12.

${ }^{32}$ See footnote 19.

${ }^{33}$ For an insightful discussion of this point, see Janiak (2008), ch. 4.
} 
discussion of nebulous stars, ${ }^{34}$ to argue that they were not single massive stars, whose elliptical form would be caused by their axial rotation, but instead clusters of very distant stars, whose elliptical configuration was analogous to the plane of the Milky Way. Kant then set for himself the goal of searching for the cause of the 'systematic constitution' of the starry heaven, from our solar system to the Milky Way and the nebulous stars farther away.

Kant introduced two possible views about the origin of the universe. The first one, taking into account all planetary motions, postulated "a cause, whatever it may be, [that] has exercised an influence throughout the whole extent of the system (...) a material cause by which they have been put into motion". The second view, on the other hand, held that the space where planets move was "entirely empty and bereft of all matter that could cause a community of influence on these heavenly bodies (...). Newton moved by this reason could allow no material cause (...). He asserted that the immediate hand of God had instituted this arrangement without the intervention of forces of nature". 35

Kant's presentation of Newton's view is of course questionable, ${ }^{36}$ and betrays the mixed reception of Newton among the Continental (French and German) intellectuals Kant was acquainted with. ${ }^{37}$ It is not my aim here to investigate whether this is an accurate picture of Newton, but rather how Kant articulated his own view by comparing it with what he took to be Newton's view.

Kant then tried to reconcile these two views - the first of which is broadly mechanical in believing in a material cause (for example, a fluid vortex) imparting motion to planets by immediate contact as opposed to action at a distance- by introducing his own view:

\footnotetext{
${ }^{34}$ Maupertuis (1732). As Aiton (1972) p. 201 pointed out, Maupertuis played a key role in spreading Newtonianism not only in the Cartesian-dominated France but also in the Continent. The 1732 work was a Newtonian manifesto against Leibniz's fluid vortex theory. Maupertuis used the classic Newtonian argument from comets against the vortex theory. He regarded comets also as responsible for the formation of both the ring and satellites of Saturn (the ring would consists of the tails of comets attracted by Saturn, while the satellites would be the bodies themselves of the comets captured in the same way). We shall see here below how Kant's view on Saturn ring differs slightly from Maupertuis' - another sign of his more nuanced approach to the Newtonianism of Principia.

${ }^{35}$ AK 1: 261.7-262.14. Kant (1755a), English translation (1968), p. 60.

${ }^{36}$ This is not the place to enter into controversial exegetical analyses of Newton's natural philosophy. It suffices to mention that Janiak (2008, pp. 113-29) has persuasively argued that Newton rejected action at a distance, despite opting for a non-mechanical analysis: there can be local action that does not involve impact via a non-mechanical concept of matter, very different from the Cartesian one (whereby matter is identified by size, shape, and motion).

${ }^{37}$ For a detailed study of the reception of Newton in the Continent, see Guerlac (1981).
} 
In the present constitution of space (...) there exists no material cause which could impress or direct their movements. The space is completely empty, or, at least, as good as empty; it must therefore have formerly been in another condition, and filled with enough of potential matter capable of transmitting motion to all the heavenly bodies found in it (...). And after attraction has cleaned up the said spaces and gathered all the scattered matter into particular masses, the planets must have continued their revolutions freely and unaltered in a non-resistant space, with the motion once impressed upon them. ${ }^{38}$

Kant reconciled the two views by, on the one side, endorsing what he took to be Newton's orthodox view about celestial space as empty and bereft of matter, and, on the other side, by availing himself of the mechanical idea of a material cause responsible for imparting the original motions to planets. So, not only did the Principia offer no cosmogony or explanation of how planets formed and began to spin. But, from Kant's viewpoint, such an explanation was not even available within the resources of the Principia. Kant's explanation of the origin of the universe is ultimately mechanical but not necessarily along the lines of Newton's mechanics in the Principia: to Kant's eyes - and to the eyes of many of his generation- Newton did not seem able to explain what set planets in motion at the very origin of the universe, apart from resorting to God's intervention.

\footnotetext{
${ }^{38}$ AK 1: 262.21-31. Kant (1755a), English translation (1968), p. 61. Emphasis added. Compare this passage with the somehow similar analysis Kant presented decades later in MAN (AK 4: 564.118) where after having claimed that the possibility of empty space within matter was excluded on dynamical grounds (because of an ether being distributed everywhere in universe and compressing matter), Kant concluded that it was not possible to settle on dynamical grounds the question as to whether "an empty space outside the world" was possible or not. However, "As for empty space in the third, or mechanical sense, it is the emptiness accumulated within the cosmos to provide the heavenly bodies with free motion. It is easy to see that the possibility or impossibility of this does not rest on metaphysical grounds, but on the mystery of nature, difficult to unravel, as to how matter sets limits to its own expansive force. Nevertheless, if one grants what was said in the General Remark to Dynamics concerning the possibility of an ever-increasing expansion of specifically different materials, at the same quantity of matter (in accordance with their weight), it may well be unnecessary to suppose an empty space for the free and enduring motion of the heavenly bodies; since even in spaces completely filled, the resistance can still be thought as small as one likes" (AK 4: 564.22-33), English translation (2004), p. 104, emphases added. In surprising continuity with Universal Natural History, Kant tried once more to reconcile the Newtonian orthodox view about cosmic space being empty, with the dynamical view of a cosmic space originally filled with infinitely weakly resisting matter as a material cause of planets' motion and offering negligible resistance to it.
} 
Kant presented his own reconciliation of the two views as more than just a hypothesis, and yet he called it a "hypothesis". 39 There could be two different explanations for it. The first is religious. Kant wanted to avoid any clash with religious authorities, and the nebular hypothesis clashed with the Christian idea of creation ex nihilo. No wonder, Kant was at pain already in the Preface to clarify how his view was compatible with religious beliefs. ${ }^{40}$ But, I want to suggest also a second explanation for presenting his view as a hypothesis: namely, the speculative character of Kant's analysis of a subtle matter diffused in cosmic space. By calling his view a "hypothesis", Kant might have signalled to his readers his allegiance to a wellrespected tradition, in which speculative hypotheses were allowed as investigative tools in scientific inquiry (despite Newton's orthodox hypothesis non fingo). In other words, it is the speculative method of Newton's Opticks —exemplarily displayed in the Queries - that fits nicely with the dynamical corpuscolarism of Kant's cosmogony. But if Kant's appeal to a fine matter originally diffused in space and to an original material cause / vortex mechanism underpinning the counterbalance of attractive and repulsive forces were not already sufficient signs of Kant's distance from Newton's orthodoxy, there is a third aspect of his cosmogony that in my view betrays his departure from Newton's Principia and his being closer to the Opticks.

Kant presented the elements of primordial matter as having different specific densities, such that those with "greater specific density and force of attraction (...) would therefore be more scattered than the lighter kinds when the material of the world was equally diffused in space". ${ }^{41}$ This analysis is germane to the dynamical corpuscularism defended by Newton in the Opticks, Book II, Part III, Proposition X, where Newton assumed that the corpuscles had different specific densities to explain the different refractive indexes of natural bodies. According to Newton, all material bodies are porous; they consist of corpuscles with irregular shapes and different densities, and, with the ether uniformly distributed both in between them and outside them. For bodies with similar specific densities, Newton explained their different refractive powers on the basis of their allegedly different proportions of sulphureous oily particles, which-he thought—were present in all bodies. So, while Kant was

\footnotetext{
${ }^{39}$ AK 1: 263.3-12. Ibid., p. 61.

${ }^{40} \mathrm{He}$ even appealed to the same "right which Descartes has always enjoyed with just judges since he ventured to explain the formation of the heavenly bodies by merely natural laws", i.e. "the formation of the world in a certain time from rude matter, by the sole continuation of a motion once impressed". AK 1: 228.21-35. Ibid., p. 15.

${ }^{41}$ AK 1: 264. 7-12. Ibid., p. 63.
} 
drawing on Newton's dynamical corpuscularism for the idea of particles with different densities, he also took the distance from what he perceived as the "inadequacy of Newton's explanation" 42 as to why near planets in the solar system are of a denser nature than the more distant ones.

According to Kant, "The scattered elements of a denser kind, by means of their attraction, gather from a sphere around them all the matter of less specific gravity" ${ }^{43}$ In this way, the scattered elements of denser kind became the nucleation sites for the formation of planetary bodies. At the same time, the elements of lighter kinds, which had not been captured by the attraction of the denser elements, tended to stay towards the centre of the system. This would explain, according to Kant, why for example the matter of the Sun is "four times lighter than that of the Earth", and why the Moon is in turn "twice denser than the Earth". ${ }^{44}$ Kant defended this "mechanical theory" against what he called the "inadequacy" of Newton's explanation of the various densities of planets as due to the "fitness of the Divine choice and the motives of the Divine purpose". 45

According to Newton, planets closer to the centre of the solar system would be denser because they would need to endure the Sun's heat, and if they had lighter density, they would ignite like comets. But, according to Kant, Newton made the mistake of confusing the density of the surface of each planet with the density of its interior, which cannot be affected by the Sun's heat. A more satisfactory explanation of why the planets have different densities did not require God's intervention or any divine choice then, but a purely mechanical explanation, in Kant's eyes. Hence, Kant took the distance not only from Newton's theological stance but also from Newton's mechanics of the Principia in some relevant aspects: or better, he took the distance from the former insofar as it was part and parcel of the latter. On the other hand, there are important aspects of the dynamical corpuscularism at work in Kant's cosmogony that betray his allegiance to a different Newton, namely to the Newton of the Opticks, as $I$ argue in the rest of this paper.

\footnotetext{
${ }^{42}$ AK 1: 238.9. Ibid., p. 27

${ }^{43}$ AK 1: 264.23-26. Ibid., p. 63.

${ }^{44}$ AK 1: 271.33-36. Ibid., p. 74.

${ }^{45}$ AK 1: 271.11-14. Ibid., p. 73.
} 
2.2 Why does Kant say that repulsive force is not 'demonstrated by the science of Newton'?

The unequivocal sign that the Principia were not necessarily the main source of inspiration for Universal Natural History can be found in the Preface:

I have applied no other forces than those of attraction and repulsion to the evolution of the great order of nature: two forces which are both equally certain, equally simple (...). They are both borrowed from the Natural Philosophy of Newton. The first is a law of nature, which is now established beyond doubt. The second, which is perhaps not demonstrated by the science of Newton with so much distinctness as the first, is accepted here only in that understanding of it which no one questions, namely, in connection with the finest dissolution of matter, as for instance in vapour. ${ }^{46}$

Mark the last sentence of this important passage. Kant here claimed that both attraction and repulsion were borrowed from Newton's natural philosophy. However, by contrast with attraction, repulsion was not demonstrated by the science of Newton, but it was accepted mainly on the basis of evidence such as the dissolution of matter in vapours. He stressed the same point in the First Chapter: "This force of repulsion is manifested in the elasticity of vapours, the effluences of strong smelling bodies, and the diffusion of all spirituous matter". ${ }^{47}$ What is the main source for Kant's repulsive force? Why did Kant say that Newton could not demonstrate repulsive force, and that the best evidence for it came from "spirituous matter"?

This could be a simple methodological remark. While Newton's analysis - the method of making experiments and observations and drawing conclusions by induction, as displayed in the Opticks-identified two fundamental forces in nature (attraction and repulsion); Newton's synthesis - the opposite method of starting from causes as established principles and deducing phenomena from them-as paradigmatically displayed in the Principia - could not mathematically derive from

\footnotetext{
${ }^{46}$ AK 1: 234.31-35, 235.1-2. Kant (1755a), English translation (1968), p. 23.

${ }^{47}$ AK 1: 265.2-4 (Elasticität der Dunste, dem Ausflusse starkriechender Körper under der Ausbreitung aller geistigen Materien). Ibid., p. 64.
} 
the two forces of attraction and repulsion all thermal, optical and other types of phenomena. But before I go on to substantiate this interpretive line, let us proceed with order and take first a look at some key passages of Universal Natural History, where Kant appealed to the repulsive force for the explanation of some phenomena.

Repulsive force is not only central to Kant's analysis of nebular vortices in the constitution of planets. It is also a key element for his analysis of: (i) comets; (ii) Saturn's ring; and (iii) solar heat. This is a particularly interesting area to explore the nature of Kant's debt to the Newtonian tradition. Cometography was a popular topic at the time. Not only did Newton resort to the great eccentricities of comets to rebut Leibniz's fluid vortex theory; but, after him, Newtonians such as de Maupertuis in the 1732 Discours expressly used comets to explain the origin of Saturn's satellites and ring. ${ }^{48}$ So, when in the Second Part, Third Chapter of Universal Natural History, Kant addressed the eccentricity of planetary orbits and the origin of comets, he was not only engaging with a well-established Newtonian literature, but also trying to find his own feet in it.

Kant seemed to be at pain to explain how the "free circulatory movements of the primitive matter" required a modification to account for the eccentricities of planetary orbits. Perhaps he felt that Newton's argument from comets applied to Leibniz's fluid vortex as much as it might have applied to his own dynamical theory of matter (with the counterbalance between attraction and repulsion engendering the circulatory motions of primordial matter). And since these circulatory motions in turn engendered planets' axial rotations as well as their rotations around the Sun, in the "systematic constitution" of the universe, Kant felt the need to address Newton's argument from comets.

To explain the eccentricities of both planetary orbits and comets, he had to "limit the hypothesis of the exact circular movement of the particles of primitive matter" so as to "allow a wider divergence from it, the more distantly these elementary particles have floated away from the Sun. (...) and the resistance of the nearer portions of this primitive matter (...) diminishes in the proportions in which these nearer particles move away under it". ${ }^{49}$ At large distances from the centre of the solar system, attractive and repulsive force were feeble, as the particles were rarer and lighter; and this would explain the eccentricities of both planetary orbits (with the

\footnotetext{
${ }^{48}$ See footnote 34 above.

${ }^{49}$ AK 1: 279.5-10. Kant (1755a); English trans. (1968), p. 85.
} 
exception of Mars and Mercury which are closer to the Sun) and comets, which formed out of the lightest particles in the most remote regions of space.

It is because of their constitution out of the lightest particles in the most remote regions of the solar system that comets present the "vapour heads and tails by which they are distinguished from other heavenly bodies. The dispersion of the matter of comets into vapour cannot be attributed mainly to the action of the heat of the Sun: for some comets scarcely reach as near the Sun as the distance of the Earth's orbit". ${ }^{50}$ Thus, contra Newton, Kant explicitly defended his own view of comets as consisting of 'vapours' of infinitely weak primordial matter, which would also explain their great eccentricities.

This explanation proved expedient to clarify in the following Fifth Chapter the origin of Saturn's ring. Like Maupertuis, Kant too defended the "comet-like nature" of Saturn's ring. ${ }^{51}$ But, once again, we should not be misguided by the prima facie Newtonianism of this claim. While for Maupertuis, Saturn's ring was a comet tail that - by falling into the sphere of attraction of Saturn — was captured by it; for Kant, Saturn's ring originated from the very same "comet-like" vaporous state or "cometic atmosphere" consisting of the lightest and weakly resisting particles, which arose from the planet surface, and continued to float around it in virtue of the momentum impressed by Saturn's axial rotation. To support his view, Kant discussed Cassini's observations of the diurnal rotation of Saturn and the ensuing ratio of gravitational and centrifugal force determining its spheroidal shape, and concluded against Newton's hypothesis of uniform density that the planet had a varying density, increasing towards the centre and with the lightest particles arising from its surface.

The varying degrees of density were in turn used by Kant to explain the solar heat in the Addition to the Seventh Chapter. In continuity with his previous analysis, Kant claimed that the Sun was a mixture of light and heavy particles, with a higher percentage of light particles (which were always more abundant in the centre of the solar system). This explained, according to Kant, why the Sun had a density four times lighter than the Earth, and why the Sun was a "flaming body and not a mass of molten and glowing matter heated up to the highest degree". ${ }^{52}$ Kant claimed that

\footnotetext{
${ }^{50}$ AK 1: 282.20-25. Ibid., p. 89.

51 “kometenähnlichen Natur”AK 1: 291.7 footnote. Ibid., p. 102.

${ }^{52}$ AK 1: 324.32-34. Ibid., p. 147.
} 
lighter, volatile particles were the "most active in maintaining fire", 53 and their higher percentage in the central body of the Sun would cause the Sun to become a "flaming", "self-active" ball.

And here it comes the most intriguing part of the story, about the nature of these lighter particles. Because they were regarded as active principles of fire, and "no fire burns without air", ${ }^{54}$ Kant concluded that there must have been air trapped inside the Sun; indeed, there must have been "elastic air" capable of "maintaining the most violent degrees of fire". And while the Sun's fire consumed and burnt "the elasticity of the atmosphere of the Sun", at the same time - to explain the self-activity of the Sun-Kant latched onto the experiments of Stephen Hales to claim that "fire also generates air by the decomposition of certain kinds of matter (...), we may suppose that in the bowels of the Sun there are many substances which, like saltpetre, are inexhaustible in yielding elastic air, and thus the fire of the Sun may be able to go on through very long periods without suffering in any considerable way from want of the accession of always renewed air". ${ }^{55}$ Hence, the self-activity of the Sun was based on Kant's surreptitious identification of the lighter particles of the primordial matter (which would abound in the Sun) with the elastic air, generated by the decomposition of saltpetre and alimenting, in turn, the solar heat.

In the following Section 3, I clarify some of the scientific sources behind this remarkable passage of Universal Natural History. I am going to show the following three main points:

(1.) the surreptitious identification of lighter primordial particles with elastic air betrays Kant's debt to Newton's Opticks (§ 3.1);

(2.) the emission of elastic air by decomposition of mineral substances (such as saltpetre) can be explicitly traced back to Stephen Hales' chymio-statical experiments in Vegetable Staticks (§ 3.2);

(3.) the further link between elastic air and the matter of fire betrays in turn Kant's debt to Herman Boerhaave's theory of fire, as I show in $\S$ 3.3 and 4, when I finally discuss Kant's essay On Fire.

\footnotetext{
${ }^{53}$ AK 1: 323.32. Ibid., p. 145.

${ }^{54}$ AK 1: 325.17. Ibid., 147.

55 "elastischer Luft", AK 1: 326.16, 326.30-33. Ibid., p. 149.
} 
Once we have clarified some of the salient themes of the speculative Newtonian experimentalism that goes from the Opticks to Boerhaave via Hales, we will be in a better position to appreciate Kant's dynamical theory of matter in 1755, in particular On Fire with its idiosyncratic blend of the aforementioned three main sources.

\section{Kant's debt to Newton's Opticks, Hales' Vegetable Staticks, and} Boerhaave's Elementa chemiae

In this section, I survey Newton's pre-Principia work on air and ether, further developed in the Opticks ( $§ 3.1$ ), Hales’ Vegetable Staticks ( $§ 3.2)$, and Boerhaave’s Elementa chemiae ( $\S 3.3$ ), in order to back up my previous claim that Kant's unorthodox use of repulsion in Universal Natural History, and in particular his claim that repulsive force was not demonstrated by the science of Newton, betray his debt to the speculative experimentalism of the Opticks. In this way, the following discussion paves the way to the final part of this paper ( $\S 4)$, where we encounter again some of the themes of speculative experimentalism exemplarily synthesized in Kant's On Fire (1755b).

Newton's philosophy of natural science has been the subject of important studies that in various ways have illuminated its complex and multifaceted nature. Despite the "hypotheses non fingo" of Principia, Isaac Bernard Cohen ${ }^{56}$ in his monograph on the legacy of Newtonianism for theories of electricity in the seventeenth century, re-evaluated the importance of the hypothesis of the ether, within the methodological framework of speculative experimentalism typical of the Queries of Opticks. Through a careful historical analysis of the sources available at the time (especially scientific lexicons), Cohen concluded that the Opticks (much more than the Principia) influenced generations of British and Continental natural philosophers throughout the eighteenth century. One of the distinctive features of the Opticks, especially evident in the Queries, is Newton's speculation about the ether as the medium for a variety of optical, thermal and other phenomena.

Newton was not in fact new to the hypothesis of the ether. In his early years, before the Principia, he had already speculated about an ethereal medium responsible for the cohesion of bodies, their elasticity, and gravitation, among others. This is

\footnotetext{
${ }^{56}$ See Cohen (1956).
} 
evident in the famous letter to Boyle on 28 February $1678 / 9,{ }^{57}$ which was first published in Thomas Birch's (1744) edition of Boyle's works. By the mid-eighteenth century, mainly thanks to the enormous influence of the Opticks in the meantime, Newton's speculations on the ether were no longer regarded as mere speculations: they became part and parcel of Newtonian natural philosophy.

Some of the themes of the letter to Boyle appeared also in another pre-Principia text, De aere and aethere, first published as part of Newton's Unpublished Scientific Papers by Hall and Hall, ${ }^{58}$ who dated it around 1674 , whereas Westfall ${ }^{59}$ dated it after the letter to Boyle and in strict conjunction with it, because of the theme of repulsion at work in the rarefaction of air and the cohesion of solids. In the next Section 3.1, I take a look at these two pre-Principia texts to support the Halls' conclusion that "The Quaeries [of the Opticks] show (...) that Newton's theory of matter had made no progress since 1687 , or even earlier, for its roots are visible in the chapter De aere written before $1675 " .60$ In particular, I concentrate on Newton's analysis of air and ether as repository of repulsive force, as presented also later in the Opticks. As the Halls noted, there was a persistent ambiguity in Newton's theory of matter between two quite distinct views: the first, clearly inspired by the dynamical corpuscularism of Boyle, took corpuscles as the repository of attractive and repulsive forces; the second resorted to the hypothesis of an ether as the ultimate repository of forces acting on corpuscles and engendering a variety of phenomena.

In a monograph on British natural philosophy in the eighteenth-century, Robert Schofield called these two views 'mechanism' and 'materialism'. ${ }^{61}$ According to mechanism, the causes of all phenomena have to be found in particles with their attractive and repulsive forces. According to materialism, the causes of all phenomena have to be found in a unique substance, the ether, as the medium of heat, electricity, vital spirit, etc. Both traditions originate from Newton's Opticks, in particular the Latin edition of 1706 and the second English edition of 1717, with two new sets of Queries (Qu. 17-24 in the second English edition, and what was later numbered as Qu. 25-31, originally added to the first Latin edition). In the next three sub-sections:

\footnotetext{
${ }^{57}$ See Boyle (1744), vol. 1, pp. 70-73.

${ }^{58}$ Hall and Hall (1962), pp. 214-28.

${ }^{59}$ Westfall (1971), ft 115, p. 409.

${ }^{60}$ Halls (1962) p. 203.

${ }^{61}$ Schofield (1970).
} 
(1) I briefly discuss the origins of these two distinct traditions from Newton's theory of matter, with a particular focus on the somehow equivalent and interchangeable role that Newton ascribed to the air and the ether as repository of repulsive force (Section 3.1);

(2) I highlight some aspects of Newton's theory of matter that had a direct influence on Stephen Hales' chymio-statical experiments, and argue that Hales' work (with some caveats) had a firm foot in the mechanical tradition that ascribed properties such as repulsion directly to particles of matter (more precisely, particles of air-see Section 3.2)

(3) I then present the influence that Hales' chymio-statical experiments, in turn, exercised on Herman Boerhaave, and how Boerhaave combined the mechanical tradition with the materialist one in his theory of fire (Section 3.3).

The continuity of themes that runs from Newton's theory of matter-as exposed in pre-Principia and Opticks - to Hales, up to Boerhaave, will not only throw light on some of the points already flagged about Kant's cosmogony, but also on Kant's On Fire (1755b), to which Section 4 is dedicated.

3.1 The Newton before the Principia on air and ether: its debt to Robert Boyle's experiments, and its continuity with Query 31 of Opticks

As mentioned above, Newtonian scholars have long recognised the continuity in Newton's theory of matter between some of the themes of his early pre-Principia works and his later mature work in the Opticks. In this Section 3.1, I want to highlight the continuity between the treatment of repulsive force (or better, its ancestor) in two texts of 1674-8 (De Aere et Aethere and Letter to Boyle, 28 Feb. 1678-9) and some salient points of the Query 31 of the Opticks. Query 31 played a very influential role in the natural philosophy of the first half of eighteenth-century, and on the young Kant too, as we shall see in Section 4. So, it is all the more relevant to identify some themes of Newton's theory of matter that run all the way from the aforementioned pre-Principia texts to the Opticks, in order to fully appreciate their relevance to Kant's dynamical theory of matter.

Among Newton's pre-Principia texts, De Aere et Aethere was probably written-according to the Halls - between 1673 (when Boyle wrote New experiments to make fire and flame stable and ponderable, to which Newton seemed to refer in the 
text), and 1675, when he wrote Hypothesis on light. Since some of the examples discussed in this text (capillary attraction, cohesion, walking of flies on water) appear also in the letter to Boyle (28 Feb. 1678-9), by contrast with the Halls, Westfall dated De Aere et Aethere at the same time as the letter to Boyle. Yet, the Halls have a point when they noted some important differences between the two texts; namely, in $D e$ Aere et Aethere Newton identified in the repulsive force of air particles the cause of all these effects, while in the letter to Boyle repulsive air did not appear at all, and instead the ether was said to be responsible for the phenomena described. Hence, the Halls' conclusion: "Newton has transferred the repulsive force from the particles of air to the particles of aether in certain cases, as he was later to do in all cases", 62

I take this observation of the Halls as the springboard for my interpretive line about the legacy of speculative Newtonianism for Kant's early dynamical theory of matter in 1755. It is my contention that the ambiguity in Newton's language between dynamical corpuscularism as the cause of phenomena versus a material ether as the repository of forces acting on passive corpuscles not only engendered the mechanical tradition of Hales' experiments on airs, and the material theory of fire in Boerhaave. But via Hales and Boerhaave, Newton's ambiguity engendered also Kant's early theory of matter in 1755, where soon some of the properties (i.e., repulsion) of the 'fine matter' diffused in cosmic space (as per Universal Natural History) became properties of an ethereal medium acting on the particles of matter and behaving as the matter of light and fire in On Fire. The upshot of the following discussion is then to highlight how Kant's early dynamical theory of matter is the hybrid result of both the mechanical and the materialistic tradition, to use Schofield's terminology, both originating from Newton's theory of matter (rather than from Newton's mechanics).

This does not amount to saying that Newton's mechanics did not treat the problem of repulsion. On the contrary, in Book II, Proposition XXIII, Theorem XVIII of the Principia Newton, for example, proved that an elastic fluid consisted of particles whose centrifugal forces were inversely proportional to the distances of their centers. ${ }^{63}$ But he also added: "whether elastic fluids do really consist of particles so repelling each other, is a physical question. We have here demonstrated mathematically the property of fluids consisting of particles of this kind, hence

\footnotetext{
${ }^{62}$ Hall and Hall (1962), p. 189.

${ }^{63}$ See Newton (1687/1713), revised translation (1934), p. 300-1. I thank John Norton for drawing my attention to this passage of the Principia.
} 
philosophers may take occasion to discuss that question". ${ }^{64}$ Newton's mechanics left open this "physical question", which fell instead under the remit of his theory of matter.

Indeed already in De Aere et Aethere, Newton had explained why two lenses tend to repel each other, why melted lead does not adhere to an iron vessel, or metallic filings float on liquids, by assuming that "the cause of this repulsion" is to be found in a "certain surrounding sphere of most fluid and tenuous matter which admits other bodies into it with difficulty...[and] as it is equally true that air avoids bodies and bodies repel each other mutually, I seem to gather rightly from this that air is composed of the particles of bodies torn away from contact, and repelling each other with a certain force". ${ }^{65}$ Not only was air identified with the "cause of repulsion", but Newton went further to distinguish three different types of airs, depending on the way they were generated:

i. vapours "arising from liquids seem to be the least permanent and the lightest"

ii. exhalations "which arise from thicker and more fixed substances, especially in the vegetable kingdom"

iii. and "air properly so called whose permanence and gravity are indications that it is nothing else than a collection of metallic particles which subterranean corrosions daily disperse from each other". ${ }^{66}$

Thus, "air properly so called", or what was also known at the time as "true permanent air", was regarded as having metallic origin, and not to be confused with vapours originating from liquids by heat, or exhalations originating from animal and vegetable substances. As examples of true permanent air being released by metals, Newton mentioned filings of lead, brass or iron dissolving in Aqua fortis; nitre ignited by charcoal, and releasing "aerial substance"; and nitre, charcoal and sulphur "as it is used in making gunpowder" whereby "almost all the substance of the mixt is changed by vehement agitation into an aerial form, the huge force of this powder arising from

\footnotetext{
${ }^{64}$ Ibid., p. 302.

${ }^{65}$ Newton (1674), in Hall and Hall (1962), p. 223

${ }^{66}$ Ibid., p. 227.
} 
its sudden expansion, as is the nature of air". ${ }^{67}$ This passage is remarkable because it anticipates some key themes that will prove important for the rest of our analysis, namely:

a. the idea of air being the cause of repulsion and being lodged in the pores of mineral, vegetable, and liquid substances;

b. true permanent air being of metallic origin and being released by fire and/or by chemical reactions with acids, such as iron being dissolved by Aqua fortis, also called at the time "spirit of nitre" - i.e. solution of nitric acid obtained by distilling at high temperatures vitriol (i.e., sulphuric acid), saltpetre (i.e., potassium nitrate), and sand;

c. gunpowder's explosions due to the expansive power of air trapped into the pores of the mineral ingredients.

Newton was not alone at the time to advance such speculations about the metallic origins of air. Robert Boyle's experiments had already distinguished between "true permanent air" and less lasting "vapours", where again gunpowder and saltpetre (potassium nitrate) were regarded as capable of releasing great quantities of air. ${ }^{68}$ The idea of air being the repository of repulsive force was part and parcel of the dynamical corpuscularism of the time. Yet, Newton soon introduced a new dimension to this mechanical tradition: the ether.

Already in the very short remaining fragment of chapter 2 of De Aere et Aethere, Newton mentioned how the air particles could in turn be "broken into lesser ones by some violent action and converted into yet more subtle air which, if it is subtle enough to penetrate the pores of glass, crystal and other terrestrial bodies, we may call the spirit of air, or aether". As evidence for the existence of the ether, Newton referred to the experiments of Boyle on calcination, whereby "metals, fused in a hermetically sealed glass for such a time that part is converted into calx, become heavier". ${ }^{69}$

\footnotetext{
${ }^{67}$ Ibid., p. 226.

${ }^{68}$ For example, in New Experiments touching the relation betwixt flame and air (1672) Boyle mentioned a mixture of gunpowder, charcoal, sulphur and saltpetre, whereby the "air... may be intercepted between the little grain of powder, whereof the mixture consists, the saltpetre itself may be supposed to be of such a texture that in its very formation the corpuscles, that compose it, may intercept store of little aereal particles between the very minute solid ones, which those corpuscle are made up of", in Boyle (1744), vol. III, p. 257.

${ }^{69}$ Newton (1674), in Hall and Hall (1962), p. 227.
} 
In New Experiments to make fire and flame stable and ponderable (1673), Robert Boyle had advanced two rather startling claims for our story. First, he had assumed that cosmic space was filled with a fluid mixture of air and ether and that celestial bodies would be floating in it "like bodies in whirlpools are carried about by their ambient" ${ }^{70}$ Second, to prove the existence of this diaphanous cosmic matter, and hence to prove that light was somehow corporeal, he described a long series of experiments on calcination of metals, whereby he concluded that the reason why metals got heavier (when burnt under a sealed container) was twofold: in some cases, the "adventitious moisture of the air" weight; but in many other cases, it would be the "flame, or igneous fluid" which would be "corporified with metals and minerals exposed naked to its action". 72 As we shall see by the end of Section 3, both claims proved important not only for Newton's later analysis of the ether, but also for the Newtonian tradition that with Stephen Hales speculated about "elastick air" being fixed into the pores of bodies, and with Herman Boerhaave identified fire as a material substance incorporated in bodies. This interpretive line will in turn illuminate why in 1755 Kant eventually identified the ether as both the matter of light and the matter of fire, in the Latin essay On Fire (Section 4).

It is no surprise then that in the letter to Boyle, 28 February 1678-9, Newton went back to the issue of an "aethereal substance" diffused everywhere and "capable of contraction and dilation, strongly elastic, and, in a word, much like air in all respects, but far more subtile". ${ }^{73}$ The step between air and ether was very short, given Boyle's characterization of the interstellar space as a diaphanous mixture of air and ether. And whereas in De Aere et Aethere Newton had identified the air as the cause of repulsion, in the letter to Boyle, he transferred to the ether this original property of

\footnotetext{
70 "First, I considered, that the interstellar part of the universe consisting of air and aether, or fluids analogous to one of them, is diaphanous; and that the aether is, as it were, a vast ocean, wherein the luminous bodies (...) swim by their own motion, or like bodies in whirlpools are carried about by the ambient" Boyle (1673) in Boyle (1744), vol. III, p. 340. Emphasis added.

${ }^{71}$ Ibid., p. 343.

${ }^{72}$ Ibid., p. 344. Further in the text, in Additional Experiments about arresting and weighing of igneous corpuscles, Boyle reversed to the language of corpuscularism and spoke of "igneous corpuscoles" instead of "igneous fluid", although the ambiguity in the language remains ("igneous effluvia"). What matters for the rest of our story is that he anticipated the same ambiguity that we will find in Boerhaave's material theory of fire, although as we shall see in Section 3.3, Boerhaave disagreed with Boyle's claim that "igneous corpuscles, that fastened themselves to the remaining matter, might be numerous enough, not only to bring the accession of weight, that was found by the scales, but to make amends for all the fugitive particles, that had been expelled by the violence of the fire". Ibid., p. 349 .

${ }^{73}$ In Boyle (1744), vol. I, p. 70.
} 
the air. By assuming that the ether could come in different densities, and it was rarer inside the pores of bodies and denser in free space, Newton speculated that "two bodies approaching one another...so as to make the ether between them begin to rarefy, ... recede from one another" ${ }^{74}$ As the rarefaction of the ether was allegedly responsible for bodies' "endeavour of receding", it was also responsible for their opposite tendency to adhere to one another whenever the density of the surrounding ether increased and pushed the bodies towards each other. Newton envisaged a balance between internal and external ether to explain how matter's endeavour to recede was counterbalanced by a tendency to adhere, beyond a certain threshold.

Most interestingly, by building on the distinction between vapours, exhalations and air he had already drawn in De Aere et Aethere, Newton used them as evidence for the 'endeavour to recede'. ${ }^{75}$ But this time it was the ether mechanism that supposedly acted among the corpuscles of bodies (be they liquid, vegetable, or mineral) to separate them and generate vapours, exhalations or air. Moreover, it was now the ether mechanism that also explained the metallic origin of "true permanent air", as the one released when, for example, a metal was poured in a solution of Aqua fortis. Newton assumed that the heavier the metallic corpuscles, the rarer the ether within the metal, and hence the greater the difference between internal and external ether responsible for keeping the metallic corpuscles separated from one another in a more permanent form. Vice versa, the smaller the particles of vapour, the denser the ether within, the easier for the vapour particles to condense back into water. Hence Newton's conclusion:

If you consider then how by the continual fermentations made in the bowels of the earth there are aerial substances rarified out of all kinds of bodies, all which together make the atmosphere, and that of all these the metallic are the most permanent, you will not, perhaps, think it absurd, that the most permanent part of the atmosphere, which is the true air, should be constituted of these. ${ }^{76}$

\footnotetext{
${ }^{74}$ Ibid., p. 71.

75 "Also that the particles of vapours, exhalations, and air, do stand at a distance from one another, and endeavour to recede as far from one another, as the pressure of the incumbent atmosphere will let them; for I conceive the confused mass of vapours, air, and exhalations, which we call the atmosphere, to be nothing else but the particles of all sorts of bodies, of which the earth consists, separated from one another, and kept at a distance by the said principle" ibid., p. 71.

${ }^{76}$ Ibid., p. 73.
} 
Newton used almost identical words decades later, when in Query 31 of the Opticks he spoke of "true permanent Air" arising by fermentation from those bodies "which the Chymists called fix'd", whose "Particles receding from one another with the greatest Force, and being most difficultly brought together, which upon Contact cohere most strongly. And because the Particles of permanent air are grosser, and arise from denser substances than those of Vapours, thence it is that true Air is more ponderous than Vapour". ${ }^{77}$ And as evidence for the repulsive force at work in true permanent air, Newton mentioned exactly the same examples he had mentioned thirty years earlier (in De Aere et Aethere) about why flies can walk on the water without wetting their feet, or two lenses resist direct contact.

Indeed, in Query 31 of Opticks, Newton famously advocated attractive and repulsive forces as two fundamental Qualities in nature, whose causes were however unknown. Evidence for them supposedly came from chemical reactions such as Salt of Tartar (potassium carbonate) attracting the "water which float in the Air in the form of Vapour", or, vice versa, Aqua fortis dissolving iron filings and liberating their particles into water "with a great Heat and Ebullition". The ether mechanism of the letter to Boyle did not feature in Query 31 to explain the latter phenomenon. There is no mention of the ether at all in this Query, and Newton seemed to revert to the language of dynamical corpuscularism of De Aere et Aethere also in the choice of his examples (e.g., why Pulvis fulminans - mixture of sulphur, nitre, and salt of tartargave a more powerful explosion than gunpowder; or why "sulphureous Steams abound in the Bowels of the Earth and ferment with minerals and sometimes take fire with a sudden Coruscation and Explosion"). ${ }^{78}$ Yet, there is not any explicit mention of the air as the cause of repulsion either. Newton contented himself with noticing how "in Fermentations the Particles of Bodies (...) are put into new Motions by a very potent Principle and (...) vanish into Air, and Vapour, and Flame". ${ }^{79}$ So, air and vapours were now evidence for a powerful Principle, as opposed to being the cause of or the repository of it. Newton identified two fundamental principles in nature:

Seeing therefore the variety of Motion which we find in the World is always decreasing, there is a necessity of conserving and recruiting it by active

\footnotetext{
${ }^{77}$ Newton (1704/1717), Query 31, ed. (1952), p. 396.

${ }^{78}$ Ibid., p. 379.

${ }^{79}$ Ibid., p. 380.
} 
Principles, such as are the cause of Gravity, by which Planets and Comets keep their Motion in their Orbs, and Bodies acquire great Motion in falling; and the cause of Fermentation, by which the Hearth and Blood of Animals are kept in perpetual motion; (...) the Caverns of the Earth are blown up, and the Sun continues violently hot and lucid, and warms all things by his Light. $^{80}$

If attraction, or better the "cause of Gravity", is one of the fundamental principles, what is the other principle, i.e. the "cause of Fermentation", animal heat, natural explosions, and the Sun's heat? It is at this point of Query 31 that in addition to attraction, Newton introduced repulsion (or what he called a "repulsive Power" or "virtue"), whose evidence for came from "the Production of Air and Vapour. The Particles (...) are shaken off from Bodies by Heat or Fermentation, so soon as they are beyond the reach of the Attraction of the Body, receding from it, and also from one another with great strength". ${ }^{81}$ And he referred implicitly to Boyle's discussion of "Particles of Air to be springy and ramous, or rolled up like Hoops" to conclude critically that none of these ingenious mechanical hypotheses could explain the vast contraction and expansion of aerial particles - 'fixed' or released from bodies - unless "a repulsive Power" was assumed. ${ }^{82}$

But there is more. In Query 31, Newton introduced these two active principles of attraction and repulsion to explain how matter in the universe could be kept in motion and avoid decaying. He referred indirectly to the Cartesian vortex theory ${ }^{83}$ to argue that "if it were not for these Principles, the Bodies of the Earth, Planets, Comets, Sun, and all things in them would grow cold and freeze, and become inactive Masses". ${ }^{84}$ Hence, his conclusion that "God in the beginning formed Matter in solid, massy, hard, impenetrable, moveable Particles, of such Sizes and Figures, and with such other Properties, and in such Proportion to Space, as most conducted to the End for which he form'd them". 85

\footnotetext{
${ }^{80}$ Ibid., p. 399

${ }^{81}$ Ibid., p. 395.

${ }^{82}$ Ibid., p. 396.

83 "Whence it is easy to understand, that if many contiguous Vortices of molten Pitch were each of them as large as those which some suppose to revolve about the Sun and the fixed stars, yet these and all their parts would, by their tenacity and stiffness, communicate their motion to one another till they all rested among themselves" ibid., p. 399.

${ }^{84}$ Ibid., pp. 399-400.

${ }^{85}$ Ibid., p. 400.
} 
We can now better appreciate why in the Preface to Universal Natural History Kant said that repulsive force "is accepted here only in that understanding of it which no one questions, namely, in connection with the finest dissolution of matter, as for instance in vapour". ${ }^{86}$ This was precisely the way Newton introduced repulsive force in Query 31 of Opticks, and also the way in which repulsive force entered in the vocabulary of British natural philosophy in the first half of the eighteenth century. But most importantly, we can also understand why Kant was not happy with Newton's reliance on God in creating a universe, where particles' sizes, properties, and proportions were ultimately the expression of God's divine plan. Hence, Kant's attempt to strike a middle ground between the mechanical (be it Cartesian or Leibnizian) tradition that resorted to a 'material cause' for explaining the origins of celestial bodies, and why they began to spin, and the similarly unsatisfactory Newtonian explanation in terms of 'divine intervention' (recall Section 2.1 above).

The air and the ether as the cause of repulsion have both gone in Query 31, but the phenomena described to back up the repulsive power are the very same phenomena that decades earlier Newton had used to ascribe a repulsive force to the air first, and to the ether then. The ambiguity in Newton's language between the dynamical corpuscularism of air and ethereal materialism engendered two important trends in speculative Newtonian experimentalism of the first half of the eighteenth century. On the one hand, Stephen Hales brought Newton's dynamical corpuscularism to the next level by rediscovering the chemical role of air as the repository of repulsive force trapped among the corpuscles of bodies. On the other hand, the idea of an ethereal diaphanous cosmic matter (or as an 'igneous fluid', to echo Boyle's expression) was hard to die, and found a new expression in Boerhaave's material theory of fire. It is via these two parallel trends that Kant's reception of speculative Newtonian experimentalism took place, and crystallized in his very idiosyncratic analysis of On Fire, as I clarify in the final Section 4. But before we turn to On Fire, let us take a quick look at these two trends, starting with Stephen Hales, who picked up on the theme of repulsive force at work in vapours and fermentations.

\subsection{Stephen Hales on 'elastick' repelling air}

\footnotetext{
${ }^{86}$ AK 1: 235.1-2. Kant (1755a), Engl. trans. (1968), p. 23.
} 
Stephen Hales' Vegetable Staticks (1727) brought the Boyle-Newton dynamical corpuscularism to the next level, making full use of attractive and repulsive forces for the explanation of vegetable, animal, and mineral fermentation processes. Most importantly, Hales rediscovered the air as the cause or the physical seat of repulsion (along the lines foreshadowed by Newton in De Aere et Aethere) and ascribed to it an important chemical role that Newton had not envisaged. In this way, an important theme of Newton's theory of matter pre-Principia found a new life and expression, and was bound to have a lasting impact on the natural philosophy of the eighteenth century.

Stephen Hales was a central figure of British natural philosophy of the time. His primary research interests were plant physiology and medicine (his other book, Haemostaticks, 1733, influenced a new generation of Oxford and Cambridge iatrochemists including John Friend and James Keill). Vegetable Staticks had a great resonance also in the Continent, ${ }^{87}$ where it was soon translated in French by Buffon, and from the French into German in 1748 with a Preface by Christian Wolff. Kant had in his library a copy of this 1748 German edition (Warda 1922: 03012. Exemplar: <4> IX B 1169 m.); and, no wonder references to Hales' Vegetable Staticks feature prominently in all Kant's works of 1754-5 (Universal Natural History, New Elucidation, On Fire as well as in the Aging Earth essay of 1754, AK 1: 208). Here I clarify what salient aspects of Hales' work influenced the young Kant, and highlight both the continuity with the Boyle-Newton corpuscularism and the novel twist Hales gave to this tradition. As we shall see by the end of this Section 3, there is an important theme that runs from Newton's theory of matter in the pre-Principia and Opticks, via Hales' Vegetable Staticks, to Boerhaave's Elementa chemiae (1732), and that provides - if my analysis is correct — the background for Kant's early dynamical theory of matter in 1755 .

In Chapter 6 of Vegetable Staticks, Hales latched onto Boyle's experiments on the production of air from the fermentation of "Grapes, Plums, Gooseberries, Cherries, and Pease". ${ }^{88}$ He used an experimental device consisting of a small retort connected to a glass vessel with a hole at the bottom and immersed in a large vessel of water. By placing the retort (containing different kinds of animal, vegetable or mineral substances) on a stove, Hales could observe the effects of combustion, with

\footnotetext{
${ }^{87}$ See Guerlac (1951).

${ }^{88}$ Hales (1727); English translation (1961), p. 89.
} 
the "expansion of the Air and the matter which was distilling". Hales could measure - through the changing level of water rushing through the hole - the quantity of air absorbed or released via the fermentation of various substances. The long series of experiments that occupy Chapter 6 was meant to demonstrate Newton's claim in Query 31 of the Opticks that "true permanent Air arises by fermentation or heat, from those bodies which the chymists called fixed, whose particles adhere by a strong attraction, and are not therefore separated and rarified without fermentation. Those particles receding from one another with the greatest repulsive force, and being most difficultly brought together, which upon contact were most strongly united" ${ }^{89}$ As we saw in Section 3.1, this was indeed a central theme of Newton's theory of matter already in the pre-Principia texts. Hales somehow revived the pre-Principia view of the air being the cause of repulsion, by making the air 'elastick'.

Hales theorised the 'elasticity' of the air — due to highly repelling air particles_normally 'fixed' by strongly attracting sulphureous oily particles (which would allegedly abound in all bodies) and lodged among the pores of animal, vegetable, and mineral substances. I want to draw attention to some points of Hales' experiments in Ch. 6 of Vegetable Staticks, which will hopefully clarify both the continuity with the Boyle-Newton dynamical corpuscularism, and the influence that Hales himself exercised on another central figure of the time, i.e. Herman Boerhaave.

Like Newton and Boyle, who explained gunpowder explosions as due to aerial repelling particles trapped in the pores of mineral substances, Hales too resorted to the same example to back up the hypothesis of 'elastick air'. By latching directly onto Boyle's experiments on nitre, ${ }^{90}$ Hales noted that Aqua fortis poured on a solution of salt of tartar "did not shoot into fair crystal of salt-petre, till it had been long exposed to the open air; whence he [Boyle] suspected that the air contribution to that artificial production of salt-petre". ${ }^{91}$ This is the reaction whereby the corrosive nitric acid ( $\mathrm{HNO}_{3}$ - known at the time as Aqua fortis or 'spirit of Nitre') combines with potassium carbonate $\left(\mathrm{K}_{2} \mathrm{CO}_{3}\right.$ - known as "salt of Tartar") to produce potassium nitrate

\footnotetext{
${ }^{89}$ Ibid., p. 94-5. Quoted verbatim from Newton, Opticks, Query 31, ed. (1952), p. 396.

${ }^{90}$ Hales quoted here verbatim Boyle "A Fundamental experiment made with Nitre" taken from Vol. I, p. 302 of an earlier edition of the works of Boyle (1725) The philosophical works of the Honourable Robert Boyle Esq by Peter Shaw (London: W. and J. Innys), 3 Volumes. In this essay, Boyle speculated about the contribution of air to the chemical production of saltpetre, although he added a note of caution: "But whether the air really contributes anything, either to the production, or figuration of saltpetre, in our experiment, I dare not yet determine" ibid., Vol. I, p. 302.

${ }^{91}$ Hales (1727). Edition used (1961), p. 103.
} 
( $\mathrm{KNO}_{3}$ - or saltpetre), a fundamental component of gunpowder. Going beyond Boyle's hesitant conclusion about the contribution of air to this chemical process, Hales offered an explanation of the "intense burning of Fire" and explosions in terms of quantity of elastic aerial particles present in various substances. Thus, 'spirit of Nitre' was supposed to have little elastic air in it, and if poured on coals, it died out; but when mixed with salt of Tartar, it reduced to nitre, and flamed (if thrown in the fire) because salt of Tartar abounded with elastic aerial particles. If this point illustrates well, I think, Hales' debt to the Boyle-Newton dynamical corpuscularism, on the other hand, Hales owed also a debt to Newton's materialistic tradition (originating from the hypothesis of ether). Or better the Newtonian ambiguity between the language of dynamical corpuscularism and the language of ethereal materialism appears in Hales too.

Recall that for Newton the ether was much rarer than the air, and the ether mechanism was supposed to act among the inert corpuscles of bodies (be they vegetable, animal or mineral ones) to separate them and generate vapours, exhalations or air; moreover, it also explained the metallic origin of "true permanent air" released when metals were dissolved in acids. In Chapter 6 of Vegetable Staticks, we hardly find any reference to the ether. ${ }^{92}$ But there is one passage, which also Schofield notices, where Hales explicitly quoted both Query 18 and Query 21 of the Opticks, in assuming that sulphur and air were acted by "that ethereal medium 'by which (the great Sir Isaac Newton supposes) light is refracted and reflected, and by whose vibrations light communicates heat to bodies'. (...) And is not this medium exceedingly more rare and subtle than the air, and exceedingly more elastick and active? And does it not readily pervade all bodies, Opticks $Q u$. 18. The elastick force of this medium (...) must be above 490,000,000,000 times greater than the elastick force of the air is, in proportion to its density, ibid., qu. 21 ".,93

I do not think this reference to the ether is marginal. The repelling elastic air of Hales is in fact perfectly consonant with Newton's ether as itself a material repository of repulsive force (recall that Newton transferred to the ether the repulsive force he

\footnotetext{
${ }^{92}$ Robert Schofield (1970) classifies Hales under the mechanical tradition of Newton's attractive and repulsive forces, and contrasts him with the materialism of Herman Boerhaave's theory of fire. According to Schofield, not only did Hales believe that the heat of fire was a mechanical "brisk vibrating action and reaction between the elastick repelling air, and the strongly attracting acid sulphur" (ibid. p. 77); he did not either support the hypothesis of the ether, which was a stronghold of materialism.

${ }^{93}$ Hales (1727). Edition used (1961), p. 162. Emphases added.
} 
had originally ascribed to the air), and as the medium of both light and heat, as per Query 18 of Opticks. ${ }^{94}$ Moreover, if we consider that by the time Kant picked up on Hales in 1755, Newton's famous letter to Boyle (28 Feb. 1678/9) had been published by almost eleven years (in 1744 with Thomas Birch's edition of the Works of Boyle), and that - as Schofield points out — the Birch edition helped reinstating the ether hypothesis, we can easily see that—from the point of view of the young Kant writing in 1755-there must have been a small step from Newton's ether (medium of light and heat) to Hales' ether (medium acting on both the 'elastick' repelling air particles and the attracting sulphureous particles). The central interpretive hypothesis of this paper is that the young Kant, in his pre-Critical theory of matter of 1755 , received the Boyle-Newton tradition, with its inherent ambiguity between the mechanical language and the materialist one, via Stephen Hales.

No wonder Kant mentioned Stephen Hales in Universal Natural History, where he speculated about the bowels of the Sun abounding of substances such as saltpetre that could release enough elastic air to aliment the combustion inside the 'flaming' Sun. ${ }^{95}$ And references to Hales' experiments on gunpowder feature also prominently in New Elucidation (1755c) to back up Kant's principle of causality, or determining ground. Indeed, in Proposition $\mathrm{X}$ of New Elucidation, where Kant exposes some corollaries of the principle of determining ground such as "(1) There is nothing in that which is grounded which was not in the ground itself', as an illustration of this corollary, Kant mentions once again Hales' experiments on elastic air and fire:

Very frequently we see enormous forces issue from an infinitely small initiating cause. How measureless is the explosive force produced when a spark is put to gunpowder? (...) In these cases (...) the efficient cause of the enormous forces is a cause that lies hidden within the structure of bodies. I refer namely to the elastic matter either of air, as in the case of gunpowder (according to the experiments of Hales), or of the igneous matter, as is the case with all inflammable bodies whatever. The efficient cause is, in these cases, unleashed, rather than actually produced, by the tiny stimulus. Elastic forces which are

\footnotetext{
94 "Is not the Heat of the warm room conveyed through the Vacuum by the vibrations of a much subtiler Medium than Air, which after the Air was drawn out remained in the Vacuum? And is not this Medium the same with that Medium by which Light is refracted and reflected, and by whose vibrations Light communicates Heat to Bodies, and is put into Fits of easy Reflexion and easy Transmission?" Newton Opticks, Query 18, ed. (1952), p. 349.

${ }^{95}$ AK 1: $326.30-33$.
} 
compressed together are stored within; and if these forces are stimulated just a little, they will release forces which are proportionate to the reciprocal pressure exercised in attraction and repulsion. ${ }^{96}$

Thus, Kant's very same criticism of Leibniz's principle of sufficient reason in $\mathrm{New}$ Elucidation and its substitution with a new principle of determining ground can be regarded as informed by the young Kant's scientific interests in speculative Newtonian experimentalism, no less than by his Pietist background. ${ }^{97}$

To sum up and conclude this subsection, Kant's idea of repulsive force at work in the production of airs and vapours is deeply rooted in the Boyle-Newton tradition, which eventually culminated in Newton's Opticks, and in the ensuing tradition of speculative Newtonian experimentalism of Stephen Hales.

We saw how 'elastick air', due to repulsive force and chemically 'fixed' in bodies, was supposed to be released via combustion and fermentation, and how both in Newton's Queries and in some passages of Hales, the ethereal medium was considered not just as the medium of light and heat, but also as the medium for the action and reaction of elastic repelling air particles and sulphureous attracting particles. Indeed, via this alleged ether mechanism, Hales concluded that

what we call the fire particles in Lime, and several other bodies, which have undergone the fire, are the sulphureous and elastick particles of the fire fix'd in the Lime; which particles, while the Lime was hot, were in a very active, attracting and repelling state; and being, as the Lime cooled, detained in the

\footnotetext{
${ }^{96}$ AK 1: 407.30-36, 408.1-4. Kant (1755c), English translation (1992), p. 33.

${ }^{97}$ Eric Watkins (2005), ch. 2, has persuasively reconstructed the philosophical background of the young Kant's work on the metaphysics of causality in New elucidation, in particular the influence of both his teacher Martin Knutzen and the other leading exponent of the Pietist movement, Crusius, in their attack against Leibniz's principle of sufficient reason and pre-established harmony. However, Watkins argues, the final result is Kant's elaboration of a metaphysics of causality that is equidistant from pre-established harmony and Crusius' physical influx theory. Kant rejected the LeibnizianWolffian distinction between derivative active and passive forces and in particular, the "Wolffian idea that active forces could be understood as grounds of changes" (p. 123), in favor of a physical monadology, where points are physical and endowed with attractive and repulsive forces. But he also rejected Crusius' physical influx view of causality as emanating from the mere existence of substances. I want to add to Watkins' analysis the following remark. With his new principle of determining ground, by endowing physical particles with repulsive force (as per Hales' experiments), Kant was defending new metaphysics of causality as grounded in nature's dynamical forces, without the need of resorting either to the pre-established harmony, or to the mere existence of substances. His dynamical theory of matter, patterned upon Newton's and Hales' experimentalism, provided then the blueprint for his metaphysics of causality; or, so I would like to suggest here.
} 
solid body of the Lime, (...) they must necessarily continue in that fix'd state, notwithstanding the ethereal medium, which is supposed freely to pervade all bodies, be continually soliciting them to action. But when the solid substance of Lime is dissolved, by the affusion of some liquid, (...) a violent ebullition ensues, from the action and reaction of these particles, till one part of the elastick particles are subdued and fix'd by the strong attraction of the sulphur, and the other part is got beyond the sphere of its attraction, and thereby thrown off into true permanent air. ${ }^{98}$

As Boyle had introduced the hypothesis of an ethereal cosmic matter in the context of his speculations about why metals got heavier during calcination processes, and concluded that the "flame, or igneous fluid" was "corporified with metals and minerals exposed naked to its action"; 99 similarly, Hales concluded that despite the mediating action of the ethereal substratum, 'fire particles' (consisting themselves of a balance of sulphureous and elastick ones) would normally be fixed in mineral substances until the elastick air were released into true air by ebullition. The step between the elastick repelling particles of air at work in fermentations, and the elastick repelling particles of fire was very short. Hales first took that step, which subsequently Herman Boerhaave developed in a new direction.

This remark is important because - as we shall see in Section 4-in On Fire, Kant defended the idea of an elastic ether as the matter of fire. My point is that the materiality of fire that we find in On Fire (but also in New Elucidation, where in the aforementioned passage Kant talked of "igneous matter" trapped in all inflammable bodies) is just the natural consequence of the Boyle-Newton tradition, via its reelaboration through Hales' chymio-statical experiments and Herman Boerhaave's theory of fire, to which I now turn.

Herman Boerhaave's materialistic theory of fire, as opposed to the BoyleNewton's overall non-materialistic theory of fire, ${ }^{100}$ played a key role in the advent of materialism in Britain ${ }^{101}$ and in the Continent (in the Netherlands and in Germany, in

\footnotetext{
${ }^{98}$ Hales (1727). Edition used (1961), pp. 162-3.

${ }^{99}$ Boyle (1673) in Boyle (1744), vol. III, p. 344.

${ }^{100}$ There are some important caveats: as far as Newton is concerned, see Query 18 and 21, where heat is indeed related to a material vibrating ether; as far as Boyle is concerned, see my remarks about the linguistic ambiguity 'igneous fluid' and 'igneous particles' in footnote 72 above.

${ }^{101}$ As Schofield (1970), p. 132, notes "physicians were, for the next half-century, to carry much of the burden in Britain of developing a materialistic experimental natural philosophy".
} 
particular). The Leiden faculty of medicine, which flourished at the very beginning of the seventeenth century with De Volder first, and Herman Boerhaave later, became a famous international centre, where generations of Continental and British physicians and chemists were educated. So we need to look briefly at this further important trend in speculative Newtonian experimentalism and its legacy for Kant's early dynamical theory of matter.

\subsection{Herman Boerhaave on air and fire}

Stephen Hales exercised a deep influence on Dutch natural philosophy, which flourished in Leiden in the first half of the seventeenth century thanks to a series of key figures, from Herman Boerhaave to William Jacob 'sGravesande, and Pieter van Musschenbroek. 'sGravesande's textbook Physices elementa mathematica (1720-1) defended Newtonianism and had two English translations by Jean Theofile Desaguliers and John Keill. Pieter van Musschenbroek's Elementa physicae (1734) became a central textbook in experimental philosophy and in 1741 was translated into English, while a German translation appeared in 1747 (Kant had a copy of the German translation-Warda 1922:05022. Exemplar: <4> X C 163 d.).

The importance of the Leiden school for spreading Newtonianism in the Continent has rightly received historians' attention, and it is not my aim here to add anything original to the existing literature. ${ }^{102}$ Instead, my more modest aim is to illustrate some points of continuity with both the Opticks and Hales' Vegetable Staticks that in my view are salient to appreciate the origins of Kant's early dynamical theory of matter. Like Newton and Hales, both 'sGravesande and Musschenbroek believed in repulsive force and explained the elasticity of the air accordingly (although there is no mention of the ether in either of these two authors).

There is one theme that runs through the three figures of 'sGravesande, Musschenbroek, and Boerhaave with a certain continuity, and that is important for the influence that Dutch Newtonianism exercised on Kant: the materiality of fire. Schofield sees in 'sGravesande and Musschenbroek's defence of the materiality of fire one of their most significant departures from Newtonian mechanics. ${ }^{103}$ 'sGravesande regarded fire as subtle, fast moving, and contained in all bodies, while

\footnotetext{
${ }^{102}$ See again Schofield (1970), ch. 7; Cohen (1956), ch. 7; Ruestow (1973), ch. 7; Metzger (1930).

${ }^{103}$ See Schofield (1970), p. $43 \mathrm{ff}$.
} 
light was the 'Newtonian archetype for material fire'; ${ }^{104}$ Musschenbroek, on his side, took fire as a fluid substance, occupying space, and adhering to bodies. He also identified the matter of light with the matter of fire, and thought that they were differing only in direction of motion. ${ }^{105}$ Both authors clearly picked up the theme of the materiality of fire from the most important figure of Dutch natural philosophy of the time, Herman Boerhaave.

Boerhaave began his career by succeeding De Volder as Professor of Medicine and Botany in Leiden in 1709; he soon became Prof. of Chemistry in 1718, post which he retained until his death in 1738 . He was one of the greatest physicians of his time, and taught several iatro-mechanists and iatro-chemists that from all over the Continent, England, and Scotland came to Leiden to study under him. His text Elementa chemiae (1732)_originating from a previous series of unauthorized students notes (Institutiones et experimenta chemiae, ca. 1724)—became a classic textbook for the chemistry of the time, underwent eighty editions and several translations in English. Boerhaave contributed to spreading Newton's natural philosophy in the Continent, despite the fierce opposition of part of the French and German establishment.

Some historians have argued that the publication of Elementa chemiae in 1732, just five years after Hales' Vegetable Staticks, allowed Boerhaave to incorporated elements of Hales' chymio-static experiments in his textbook. Milton Kerker, for example, has argued against Hélène Metzger's (1930) study on Boerhaave that she omitted mention of the conspicuous discussion of Hales' work in Boerhaave's text, and how Boerhaave did support Hales' views on the chemical role of air. ${ }^{106}$ Indeed, not only did Boerhaave build up on Newton's speculations in the Opticks to defend the idea of an ethereal medium penetrating all bodies and diffused in space. ${ }^{107} \mathrm{He}$ also built up on Hales to defend the chemical role of air, in the first volume of his Elementa chemiae. What matters for our purpose here, is to clarify how Boerhaave gave a new twist to the Boyle-Newton-Hales dynamical corpuscularism by stressing

\footnotetext{
${ }^{104}$ Ibid., footnote 91.

${ }^{105}$ Ibid., footnote 91.

${ }^{106}$ Kerker (1955), p. 40.

107 To this purpose, Cohen (1956), p. 223, gives a quote from Shaw's 1741 English translation of Boerhaave's text where Boerhaave presents Newton's hypothesis of a fine, subtle, elastic ether not just as a speculation but as a convincing demonstration, and adds "These notes reinforce the view that the Newtonian scientists of the eighteenth century were convinced that Newton's positive views were to be read in the Queries of the Opticks".
} 
the materialistic tradition instead, and how the end product of this re-elaboration of Hales via Boerhaave influenced Kant's On Fire.

In the first volume of Elementa chemiae, Boerhaave discussed transitions of physical state, and in particular the boiling point of water. He referred to the experiments of Guillaume Amontons in Memoirs de l'Académie Royale des Sciences demonstrating the correlation between the weight of atmospheric pressure and the boiling point of water: namely, that the "more closely the parts of water are compressed together by the increase of the incumbent weights, the more fire will be required to make them recede from one another; in which consists ebullition". ${ }^{108}$ In this same context, Boerhaave mentioned also Fahrenheit's discovery that the amount of heat required to boil water increased when the atmospheric pressure was considerable (e.g., at the seaside) and decreased when the pressure was lighter (e.g., on top of mountains). As we are going to see in the final Section 4, Kant's reference to Amontons and Fahrenheit on precisely this point in On Fire, betrays explicitly his reliance on Boerhaave's text.

As a result of these observations on transitions of physical state and the boiling point of water, Boerhaave concluded that fire was an element ${ }^{109}$ that "it must always be present in every part of space... Nor does Fire thus exist only in every part of space, but it is likewise equally diffused through every Body, the most solid, as well as the rarest", and its "most peculiar character" is "its property of rarefying Bodies". ${ }^{110}$ Therefore, fire cannot be "created, or generated de novo, nor is there any destroyed when it is extinguished; (...) nor perhaps has it any weight". ${ }^{111}$ In taking fire as an imponderable material fluid, Boerhaave was in a way continuing the tradition of Boyle's New Experiments to make fire and flame stable and ponderable (1673) about an "igneous fluid". However, whereas Boyle believed that the igneous fluid were "corporified with metals and minerals""112 in calcinations; Boerhaave expressly took the distance from Boyle in considering the fire imponderable. Instead, he ascribed the additional weight of metals in calcinations to a corrosive Sulphur, abounding in materials such as antimony, lead, tin, iron, and "rubbing of the particles

\footnotetext{
${ }^{108}$ Boerhaave (1732), Eng. translation (1735), vol. 1, p. 104.

${ }^{109}$ Ibid., p. 104.

${ }^{110}$ Ibid., p. 113.

${ }^{111}$ Ibid., p. 211.

${ }^{112}$ Boyle (1673) in Boyle (1744), vol. III, p. 344.
} 
of the other bodies, and thus mixing them with the matter to be calcinated". ${ }^{113}$ These peculiar features of fire, as an elementary material fluid, diffused everywhere, present in all bodies and capable of rarefying them, echo the very similar features that Hales ascribed to air. As mentioned above, the step from the elastic repelling particles of air at work in Hales' fermentations, to the elastic repelling fire at work in Boerhaave's transitions of physical state was short, and can be summarized in the five main points here below:

i. like Hales, Boerhaave too associated air with repulsive force ("the Air resisting the motion with a remarkable repulsive force, immediately manifests itself to be a hard body"). ${ }^{114}$

ii. repulsive force was in turn identified with the "peculiar property of air", namely its "elasticity, by which all known Air, possessing a certain space, and being confined there in such manner that it cannot escape, will, if it is pressed together by a determined weight, reduced itself into a less space...[and] by a spontaneous expansion, recover again the space it hath lost, in proportion, as the compressive force is diminished". 115

iii. The elasticity of air was not an intrinsic property of a single particle of air, but instead a relational property requiring at least two particles. ${ }^{116}$ In this context Boerhaave referred to Boyle's experiments to prove the elastic power of the air, and gave his own original twist to this theme inherited from Boyle and Hales. ${ }^{117}$

iv. Boerhaave directly referred to Hales' Vegetable Staticks, in particular his chapter six, in relation to the air being 'fixed' in bodies and released by fire in combustion processes. ${ }^{118}$

\footnotetext{
${ }^{113}$ Boerhaave (1732), Eng. Translation (1735), vol. 1, p. 212.

${ }^{114}$ Ibid., p. 252.

${ }^{115}$ Ibid., p. 259.

116 "This Elasticity then only has being, when two such Particles of Air come to touch and repel one another; ...if these elastic aerial Particles were so far distant from each other...this repelling force should utterly cease. (...) One aerial Particle, therefore, would have nothing of this elastic power; but it would be only the joint effort of several", ibid., p. 264.

${ }^{117}$ Kant's idea of repulsive force as an elastic force that manifests itself in vapours and spirituous substances is then borrowed both from the Boyle-Newton-Hales tradition and from Boerhaave, where the latter provided the background for Kant's idea of repulsive force as a relational property of matter (i.e. it increases at short distances, and decreases at large distances). In Physical Monadology, Kant for example measured the strength of the repulsive force as proportional to the inverse ratio of the cubes of the distances from the centres of the physical monads (AK 1: 484.31-33).

118 "By Fire, therefore, at least, elastic Air is always separated from those Bodies; and consequently such a matter was in them before, though whilst it was lock'd up there, it did not produce the effects of Air (...) But having seen, and to my advantage perused, a very elaborate treatise, published about two
} 
v. Hence, the interchangeable role of air and fire was easily forged. Not only was fire responsible for releasing Hales' elastic air fixed in solid bodies, but also vice versa: "Fire which puts all things in motion, can scarcely be either collected, preserved, directed, increased, or moderated, without Air". 119

Stephen Hales' elastic air, as the repository of repulsive force, finds then its counterpart in Boerhaave's material fire. Like Hales' air-which was an elastic matter chemically 'fixed' in the pores, and released upon combustion and fermentation-, similarly, Boerhaave's fire was an elastic matter penetrating all bodies and rarefying them. $^{120}$

Metzger, in her classic 1930 study on Boerhaave, quotes Duhem in identifying Boerhaave's material fire as the ancestor of Boscovich's dynamical theory of matter, whereby matter is endowed with attractive and repulsive forces, the former understood in terms of gravitation and the latter in terms of imponderable fluids such as caloric. ${ }^{121}$ This is also the interpretive line that I would like to suggest here below: behind Kant's early dynamical theory of matter in 1755 (elaborated independently of Boscovich's) lays the interpretation of repulsive force as a subtle elastic fluid surrounding particles of matter (among which attraction acts). The 'sphere of activity' of Kant's physical monads ${ }^{122}$ is not that different from the sphere of activity of imponderable fluids, such as the electric fluid or the caloric fluid. And it derives from Boerhaave's defence of the materiality of fire as a subtle, elastic, and weakly repulsive fluid at work in all transitions of physical state.

It is with Boerhaave that fire was classified among the material elements: in the preceding corpuscular philosophy of Boyle (and even more so Descartes), fire was regarded as a consequence of the vibratory motions of particles. ${ }^{123}$ Newton himself held contradictory views on heat (sometimes described as a brisk motion of particles, and other times, notably in Query 18, as the vibratory motion of the ethereal medium

years ago by the famous Dr Steph. Hales, called Vegetable Statics, (...) I chose rather to refer you to that work", Boerhaave (1732), English trans. (1735), vol. I, p. 314.

${ }^{119}$ Ibid., p. 247. This last point provided the inspiration for Kant's analysis of the self-activity of the Sun in Universal Natural History (as we saw in Section 2.2).

${ }^{120}$ Incidentally, Boerhaave's view anticipated in this way Lavoisier's imponderable fluid of caloric (no wonder Lavoisier paid tribute to Boerhaave in his treatise on chemistry).

${ }^{121}$ Metzger (1930), p. 56.

${ }^{122}$ AK 1: 481.9-11.

${ }^{123}$ For Boyle's terminological ambiguity between fire as a fluid substance vs. vibratory motion of corpuscles, see footnote 72 above. 
of light, as mentioned above). Although Boerhaave fell short of identifying the matter of fire with the matter of light by contrast with s'Gravesande and Musschenbroek, ${ }^{124}$ his materialistic view of fire originates from Newton's Queries. ${ }^{125}$

It is in this historical and cultural context at the end of the 1740 s and beginning of 1750 s that the young Kant began to use Newton's ether of the Queries as the medium of both light and fire, in a short Latin essay entitled De igne, to which I now finally turn, as it synthesizes all the themes of the Boyle-Newton-Hales-Boerhaave tradition I have explored so far.

\section{Succint Exposition of Some Meditations on Fire}

In Section 3, I made the case for the following four main points:

1. in some pre-Principia works and in the Opticks, Newton ascribed an equivalent role to the air first, and the ether then as repository of repulsive force; indeed, he transferred the repulsive force originally attributed to the particles of air to the ether.

\footnotetext{
${ }^{124}$ As Metzger (1930), p. 213, pointed out, Boerhaave did not identify fire and light because he thought that there were phenomena where fire was mostly present (as a hot poker) which nonetheless did not emit light, and vice versa optical phenomena such as moonlight where no fire could be found. A similar distinction between light and fire can also be found in other authors of this period. Johann Eberhard, for example, in Erste Gründe der Naturlehre (1753) distinguished between fire and light, since light is more subtle than fire $(\S 318)$ and claimed that "elementary fire appears to be a fluid and highly subtle essence that is spread out through the entire universe and sinks in according to the laws of fluid bodies wherever it meets with the least resistance" ( $\$ 311$, p. 314; I thank Eric Watkins for drawing my attention to Eberhard's text, and for kindly providing me with a copy of this text). Kant used Eberhard's text in his first semester as Privatdozent in 1756, so one may conjecture that he must have been familiar with this text by the time he was writing On Fire, and that it might have been this text to influence his view about fire as an elementary fluid. I have two obervations here in response. The first is methodological. Throughout this paper, especially in this long Section 3, I have never meant to engage in the rather daunting endeavour of exploring through which channels Kant might have received Newtonian experimentalism (e.g., via possible teachers at the Albertina at the time, be it Johann Gottfried Teske, Karl Rappolt, or others). Other scholars have done work in this area, to which I can hardly add anything (see, just to mention two examples, Kuehn 2001, and Pozzo and Oberhausen 2002). My methodological strategy in this paper was to stick to Kant's texts directly and to the sources quoted there explicitly, in order to reconstruct some of the themes of the Newtonian experimental tradition that in my view inspired his peculiar treatment of repulsive force as early as 1755 . Coming to my second observation, even if one could arguably claim that Kant's analysis in On Fire was influenced by Eberhard (Kant did not mention him in the text, whereas he did mention Newton's Opticks, Hales, and Boerhaave), it would not challenge the interpretive analysis here offered because the case could be made for reconducing Eberhard's theory of material fire back to the cultural milieu dominated by Boerhaave, as is also the case with 'sGravesande and Musschenbroek .

${ }^{125}$ As for the debt to Newton's Opticks, Boerhaave is explicit: "Is the cause of this the affinity there is betwixt Fire and Inflammable Oils? ...you will see by and by, what a vast deal of pains I have taken to resolve these Queries: and I think it will be evident, that they ought all to be considered...See the incomparable Newton in his Opticks", Boerhaave (1732), Engl. translation (1735), vol. I, p. 105.
} 
2. This shift in Newton's natural philosophy engendered a persistent ambiguity between dynamical corpuscularism (as the mechanical view of corpuscles endowed with repulsive force) and a material ether as the ultimate repository of repulsive force acting on passive corpuscles.

3. The two traditions of mechanism and materialism-both originating from Newton's theory of matter-find their expression, respectively, in the mechanical tradition of Hales' experiments on airs (with the caveats we saw in Section 3.2), and the material theory of fire by Boerhaave.

4. The step from Hales' elastick repelling particles of air at work in fermentations, to Boerhaave's rarefying material fire at work in transitions of physical state was short.

In this final Section 4, I am going to show how via Hales and Boerhaave, Newton's ambiguity between dynamical corpuscularism and ethereal materialism directly influenced Kant's early theory of matter in 1755, where soon some of the properties (i.e., repulsion) of the 'fine matter' diffused in space of Universal Natural History became properties of an ethereal medium acting on the particles of matter and behaving as the matter of light and fire in On Fire. Kant's early dynamical theory of matter can then be regarded as the hybrid result of the mechanical and the materialistic traditions, both originating from Newton.

Kant wrote the short Latin essay De igne in the spring 1755 as his Magisterarbeit. There is a lot of continuity between the mechanical approach of whirling particles championed in Universal Natural History and On Fire. In the latter, Kant spelled out the chemistry underlying the mechanism envisaged for his cosmogony, and clarified the nature of the primordial fine matter "widely diffused in the celestial space". But precisely in the light of the aforementioned intertwining of mechanical and materialistic tradition, On Fire is dedicated to the ether as the medium of light and heat: most of the phenomena, which were discussed in terms of dynamical corpuscularism in Universal Natural History (from the elasticity of the atmosphere of the Sun to the formation of Saturn's rings), in On Fire find their ultimate explanation in Kant's analysis of changes of physical state and combustion in terms of a material ether. Hence, this short Latin essay occupies a central role in understanding the development of Kant's early dynamical theory of matter in 1755, and beautifully exemplifies the idiosyncratic combination of the various sources we have explored so far. 
That Kant is taking the distance from the Newtonian dynamical corpuscularism of Universal Natural History, but also from the mechanical tradition of Descartes and the atomists is evident at the outset of On Fire, where he argued that the fluidity of bodies could not be explained by the division of matter into smooth minute particles, but it required instead a "mediating elastic matter, by means of which they communicate the force (momentum) of their weight equally in all directions". 126 Elastic matter (materia elastica) had to be intermixed with corpuscles to explain the elasticity of solid bodies, i.e. why they resisted weights attached to them without easily breaking; or elastic properties of springs as per Hooke's law. Section I of On Fire is dedicated to the nature of solid and fluid elastic bodies, with a series of demonstrations more geometrico of how any kosher mechanical philosophy à la Descartes could not explain the elasticity of solid bodies, even less so their rarefaction and changes of physical state, unless an elastic matter was assumed (as consonant with the materialistic tradition).

Like Boerhaave, Kant too saw the force of fire as being manifested primarily in the expansion and rarefaction of bodies. ${ }^{127}$ And as Boerhaave defended the materiality of fire, similarly Kant identified the elastic matter lodged in the interstices of bodies with the matter of fire:

Proposition VII. The matter of fire is nothing but the elastic matter (...) which holds together the elements of bodies with which it is intermixed; its undulatory or vibratory motion is that which is called heat. ${ }^{128}$

And as evidence for the elastic matter of fire, Kant analysed the phenomenon of boiling as due to the elastic matter trapped in the liquid body, and acquiring enough force to overcome attraction, and be released in the form of elastic bubbles.

From the identification of the elastic matter of bodies with the matter of fire, to the subsequent identification of the matter of fire with the ether itself, the step is short: "Proposition VIII. The matter of heat is nothing but the aether (the matter of light) compressed by a strong attractive (adhesive) force of bodies into interstices". ${ }^{129}$ This is a remarkable proposition in which the ether / elastic matter is effectively identified

\footnotetext{
${ }^{126}$ AK 1: 372.06-11. Kant (1755b), English trans. (1986), p. 17.

${ }^{127}$ AK 1: 371.9-10, 376.5-6.

${ }^{128}$ AK 1: 376.18-21. Kant (1755b), Engl. trans. (1986), p. 23.

${ }^{129}$ AK 1: 377. 16-18. Ibid., p. 24.
} 
both with a Boerhaavian matter of fire, whose vibratory undulations are heat, and with the Newtonian matter of light. ${ }^{130}$

After Proposition VIII, to support the view of the ether as the matter of light and fire, Kant referred to Newton's optical experiments, in particular to the fact that the attraction of oily sulphurous particles responsible for light refraction was also responsible for holding the matter of fire tightly trapped in the interstices of bodies:

For oils (for instance, oil of turpentine) which according to the experiments of Newton and many others, reflect rays of light (i.e. attract them) much more than can be explained by their specific gravity, likewise have a boiling point far higher than can be explained by their specific gravity. Oils are the true fuels of flames, and in this state they scatter light in all directions. Thus is shown that the matter of heat and the matter of light agree as closely as possible, or rather, that they are not different. ${ }^{131}$

As mentioned above, Newton believed that the different refractive powers depended on different proportions of sulphurous oily particles inside bodies. He also believed that sulphurous matter was important for combustion and linked "fat sulphurous unctuous bodies" to both refraction and combustion in Book II, Part III, Prop. X of Opticks.

But Newton fell short of identifying the matter of light with the matter of heat. Although in Query 19, he resorted to the ether as an optical medium, whose different densities explained the refraction of light, and in Query 18 even took the ether as the medium whose vibrations transmitted heat, Newton never explicitly identified fire as the "matter of heat", i.e. as a material substance. The materiality of fire betrays instead Kant's debt to Herman Boerhaave's Elementa chemiae.

So, effectively, Kant operated an idiosyncratic combination of Newton's optical ether (responsible for light reflection, refraction, and thin films) with Boerhaave's material fire, although neither Newton identified fire as a material substance nor did

\footnotetext{
${ }^{130}$ If we consider that more than forty years later, in the Opus postumum, Kant still identified the ether as the 'matter of heat' or Wärmestoff, and thought that it was responsible for all changes of physical state as well as for light transmission, we can get an idea of the scientific origins of Kant's peculiar view as rooted in his idiosyncratic combination of Boerhaave's theory of fire, Hales' view on elastic air, and Newton's Opticks.

${ }^{131}$ AK 1: 377. 31-37. Kant (1755b), English trans. (1986), p. 24.
} 
Boerhaave identify fire with light. But what evidence did Kant have for identifying the ether as both the matter of fire and the matter of light?

Kant latched onto Euler's Nova theoria lucis et colorum "according to which light is not the effluvium of shining bodies but is the propagated pressure of the aether which is dispersed everywhere", ${ }^{132}$ and linked it with his own use of the ether as the matter of fire, via the example of the transparency of glass. Given the transparency of glass and its ability to refract light, since glass is obtained by fusing at high temperatures potash with sand, Kant concluded that the matter of fire-which must be largely dispersed among the glass' solid elements - must be one and the same with the ether, or the matter of light.

And to measure the force of fire that manifests itself in the rarefaction of bodies, Kant referred to Guillaume Amontons' report in the Mémories de l'Académie Royale des Sciences whereby the degree of heat was measured "by the elastic force of the air expanded by this heat; that is, by [measuring] the weight which is capable of being supported by the same volume [of air] possessed of this heat". ${ }^{133}$ If this mention of Amontons already betrays - in my view-Kant's reliance on Boerhaave's text, even more explicitly later in the text Kant referred to Boerhaave's Elementa chemiae to report Fahrenheit's experiments about the changing boiling points of liquids (depending on the atmospheric pressure), followed by a reference to Pierre Charles le Monnier's experiments using a Reaumur thermometer to measure different boiling points of water in Bordeaux and Pic du Midi, and similar experiments by JeanBaptiste Baron de Secondat. ${ }^{134}$

It is here that Kant's debt to Boerhaave becomes manifest in the specific way in which Kant devised an explanation for the change of water from liquid to vapour. As Boerhaave used the experiments of Amontons and Fahrenheit to claim that atmospheric pressure compressed the force of fire and prevented the flame from dissipating through some sort of action and reaction; similarly, Kant claimed that it was via the action and reaction between the weight of the atmospheric pressure and the "undulatory motion of the particles of fire" that the elastic ethereal matter was stably lodged in the pores of bodies. As soon as either the attraction among the corpuscles decreased or the weight of the atmospheric pressure diminished (as it

\footnotetext{
${ }^{132}$ AK 1: 378.3-5. Ibid., p. 24.

${ }^{133}$ AK 1: 378.28-30. Ibid., p. 25.

${ }^{134}$ AK 1: 378.32-38.
} 
happens on mountains), the "aether by its elastic force at the boiling point succeeds in its striving to escape from its connection with the water". ${ }^{135}$ Note here how Kant's language ambiguity between the "particles of fire" (particularum ignearum) and the ether (äther) echoes once more the ambiguity we have already found in Boyle, Newton, and Hales on this point, and it exemplifies Kant's borrowing of elements from both the mechanical and the materialistic tradition.

In this same context, Kant mentioned once again Hales: "all plants, the spirit of wine, animal stone, and many kinds of salts, especially nitre, [that] release an immense amount of elastic air when strongly affected by fire, as Hales in his Vegetable Staticks instructs us with wonderful experiments". ${ }^{136}$ Kant referred once more to chapter 6 of Hales' 1727 work to conclude that "Air is an elastic fluid, almost a thousand times lighter than water", and that "It is self-evident that air extracted from these bodies by the force of fire did not have the nature of air (i.e. was not an elastic fluid possessing elasticity proportional to its density) as long as it was a part of their mass. Thus the matter expelled from the interstices of the body (...) shows elasticity only when liberated". ${ }^{137}$

Moreover, Kant referred also to Newton's aforementioned distinction between exhalations and vapours (see Section 3.1 above) and explained their "wonderful elasticity" in terms of their particles strongly repelling each other. ${ }^{138}$ As Newton had distinguished between true permanent air, exhalations, and vapours, whereby the first was supposed to arise from the dissolution of metals in acids, similarly Kant advanced what he called "an opinion... worthy of their [physicists] most accurate investigation: whether air is anything but the most subtle exhalation of the acid disseminated through all nature which manifests elasticity at any degree of heat, however small". ${ }^{139}$ So, like Newton, Kant too believed that true air ultimately originated from acid as "the most active and strongest principle by the attraction of which the aether is held together"; that is, the "true magnet of aetherial matter which holds all bodies together". ${ }^{140}$ But where does all this discussion leave us? And what good is it to understand Kant's early dynamical theory of matter in 1755 ?

\footnotetext{
${ }^{135}$ AK 1: 379.12-13. Ibid., p. 26

${ }^{136}$ AK 1: 381.28-32. Ibid., p. 29.

${ }^{137}$ AK 1: 381.35-38, 382.1-7. Ibid., p. 30.

${ }^{138}$ AK 1: 380.1-4.

${ }^{139}$ AK 1: 382. 22-24. Ibid., p. 30.

${ }^{140}$ AK 1: 382.10-12. Ibid., p. 30.
} 


\section{Concluding remarks}

Kant's dynamical theory of matter can receive new light if we consider carefully the scientific background, against which Kant came to elaborate his view very early on in his academic career. It was not my goal to provide an analysis of his dynamical theory of matter from the pre-Critical writings of 1755, to the Critical period (Metaphysical Foundations) and Opus postumum. Instead, my more modest goal was to identify some key aspects of speculative Newtonian experimentalism behind Kant's early dynamical theory of matter in 1755, especially his peculiar analysis of repulsive force, and to investigate how he came to elaborate his very own brand by extensively drawing on a popular tradition that goes from Boyle to Newton, from Hales to Boerhaave. What we have found is that Kant borrowed and adapted Newton's optical ether and Hales' elastic air and employed them in ways that neither Newton nor Hales envisaged. In the mid-eighteenth century, chemistry provided the most insightful source of knowledge for optical, thermal, and electrical phenomena. Kant's idea of repulsion as an elastic expansive force is deeply rooted in Newton's Opticks, and in the ensuing tradition of experimental Newtonianism that thrived both in England and in the Netherland.

This important experimental tradition - which dealt with the matter of fire, wondered about the elasticity of air, and believed in an ethereal fluid as the repository of repulsive force (interchangeably with air) - is at quite a distance from the Newtonian mathematical physics that we are so accustomed to associate with Kant's philosophy of natural science. It causes almost a sense of embarrassment in Kant's commentators to the point that Lewis Beck, in the Introduction to the English translation of On Fire, felt the need to clarify that Kant's dissertation is the end of a long tradition that was about to be overthrown by Priestley, Lavoisier, and Rumford. However, we should not forget the pivotal role that speculative Newtonian experimentalism played for the chemical revolution at the end of the eighteenth century. Stephen Hales and Herman Boerhaave paved the way to Joseph Priestley, Joseph Black, and Henry Cavendish's pneumatic chemistry. The seeds of the chemical revolution can be found in the experimental Newtonianism that flourished in Leiden, Cambridge, and Oxford.

The leitmotiv that links repulsive force, air, ether, and a variety of chemical phenomena reveals - if my interpretive analysis here is correct - the real nature of 
Kant's much celebrated conversion to Newton. The Newton Kant owed a debt to was not necessarily or exclusively the Newton of the first edition of Principia, i.e. the Newton that championed the new mathematical physics; but instead the much more controversial Newton of the Opticks, who ruminated on chemistry and on the possible ether-mechanism behind chemical phenomena. If we further consider that again in the Opus postumum Kant tried to prove a priori the existence of the ether in conjunction with his speculations on chemistry, we can envisage the far-reaching legacy of this leitmotiv in the evolution of Kant's philosophy from the 1750s to the 1790s.

Apropos of Newton's ether, Westfall famously observed that "composed of particles repelling each other, the aether embodied the very problem of action at a distance which it pretended to explain". In particular, Westfall argued that Newton's ambiguity on the ether (against which he had abundantly written in Book II of first edition of Principia) can be explained by bearing in mind that there was another candidate in Newton's natural philosophy for the semi-mechanical and semidynamical role of the ether, namely God himself as an "incorporeal aether who could move bodies without offering resistance to them in turn", ${ }^{141}$ which is perfectly germane to Newton's idea of absolute space as the sensorium of God.

If Westfall's analysis is right, it would also explain why the young Kant in 1755 , by rejecting the Newtonian absolute space as the sensorium of God, had to resurrect the idea of a material ether. Newton's God as an 'incorporeal aether' was simply precluded to the young Kant. No wonder, he expressly took the distance from Newton's theological stance in Universal Natural History, and repeatedly begged to differ from Newton on the role of divine intervention in the creation of heavenly bodies. If my interpretive analysis is correct, Kant's stance on the ether in the 1755 writings would then not only illuminate the nature of his debt to Newton, but also their parting of the ways as far as theology is concerned. But this is another story that I leave for future investigation.

\section{Acknowledgements}

This paper was originally presented at University of Notre Dame, University of Bonn, and UCL. I am grateful to Karl Ameriks, Katherine Brading, Robert DiSalle, Don Howard, Robby Gustin, Brigitte Falkenburg, Andrew Janiak, and Chris Smeenk for

${ }^{141}$ Westfall (1971), p. 397. 
comments on earlier versions of this paper. A special thank to Eric Watkins, who kindly commented on this paper at the UCL workshop on Philosophy of natural science from Newton to Kant and offered precious suggestions. I am also grateful to Silvia De Bianchi, whose collaboration on Kant's pre-Critical philosophy of nature, prompted me to write this paper. Finally, I thank two anonymous referees of this journal for very detailed feedback on earlier versions of this paper, which helped me refine some key points.

\section{References}

Adickes, E. (1924) Kant als Naturforscher (Berlin: de Gruyter).

Aiton, E. J. (1972) The vortex theory of planetary motion (London: MacDonald \& Co.)

Bertoloni Meli, D. (1993) Equivalence and Priority: Newton versus Leibniz (Oxford: Clarendon Press).

Boerhaave, H. (1732) Elementa chemiae, quae anniversario labore docuit, in publicis, privatisque, scholis (Lugduni Batavorum, apud Isaacum Severinum), 2 vols. English translation by T. Dallowe (1735) Elements of chemistry: being the Annual Lectures (London: J. Pemberton et al.).

Boyle, R. (1672) New Experiments touching the relation betwixt flame and air, in Boyle (1744) The Works of the Honourable Robert Boyle, ed. Thomas Birch (London: A. Millar), Volume III, pp. 248-260. (1673) New Experiments to make Fire and Flame stable and ponderable in Boyle (1744) The Works of the Honourable Robert Boyle, ed. Thomas Birch (London: A. Millar), Volume III, pp. 340-349. (1725) The Philosophical Works of the Honourable Robert Boyle, ed. Peter Shaw (London: W. and J. Innys), Volumes 3. (1744) The Works of the Honourable Robert Boyle, ed. Thomas Birch (London:

A. Millar), Volumes 5.

Carrier, M. (1990) "Kants Theorie der Materie und ihre Wirkung auf die zeitgenössische Chemie”, Kant-Studien 81, 170-210. 
(2001) 'Kant's mechanical determination of matter in the Metaphysical

Foundations of Natural Science", in E. Watkins (ed.) Kant and the Sciences

(New York: Oxford University Press), 117-135.

Cohen, I. B. (1956) Franklin and Newton. An Inquiry into Speculative Newtonian Experimental Science and Franklin's work in Electricity as an Example thereof (Philadelphia: The American Philosophical Society)

Eberhard, J. P. (1753) Erste Gründe der Naturlehre (Halle).

Edwards, J. (2000) Substance, Force, and the Possibility of Knowledge. On Kant's philosophy of material nature (Berkeley: University of California Press).

(2004) “One more time: Kant's metaphysics of nature and the idea of transition" in C. Ferrini (ed.) Ereditá Kantiane (1804-2004): Questioni emergenti e problemi irrisolti (Rome: Bibliopolis), 155-88.

Förster, E. (2000) Kant's final synthesis (Cambridge, Mass.: Harvard University Press).

Friedman, M. (1992a) Kant and the Exact Sciences (Cambridge, Mass.: Harvard University Press).

(1992b) "Causal laws and the foundations of natural science", in Paul Guyer (ed.) The Cambridge Companion to Kant (Cambridge: Cambridge University Press), 161-99.

(2006) "Philosophy of natural science", in P. Guyer (ed.) The Cambridge Companion to Kant and Modern Philosophy (Cambridge: Cambridge University Press), 303-341.

'sGravesande, W. J. (1720-1) Physices elementa mathematica. English translation by J. T. Desaguliers (1726) Mathematical Elements of Natural Philosophy Confirmed by Experiments; or, an Introduction to Sir Isaac Newton's Philsoophy (London: J. Senex, and W. and J. Innys), 3rd ed., 2 vols.

Guerlac, H. (1951) “The Continental Reputation of Stephen Hales", Archives internationals d'Histoire des Sciences 4, 393-404. (1981) Newton on the Continent (Ithaca: Cornell University Press).

Hales, S. (1727) Vegetable Staticks: or, an Account of some Statical Experiments on the Sap in Vegetables: being an essay towards a Natural History of Vegetation. Also a Specimen of an attempt to analyse the air, by a great variety of chymiostatical experiments; which were read at several meetings before the Royal 
Society (London: W. and J. Innys, and T. Woodward). Edition with a foreword by M. A. Hoskin (1961), (London: Oldbourne).

Hall, A. R. and Hall, M. B. (1962) Unpublished Scientific Papers of Isaac Newton (New York: Cambridge University Press).

Huygens, C. (1673) Horologium oscillatorium (Paris). English translation by R. J.

Blackwell (1986) The Pendulum Clock (Iowa State University Press).

Janiak, A. (2008) Newton as Philosopher (Oxford: Oxford University Press).

Kant, I. (1747) Gedanken von der wahren Schätzung der lebendigen Kräfte und Beurtheilung der Beweise,deren sich Herr von Leibniz und andere Mechaniker in dieser Streitsache bedient haben, nebst einigen vorhergehenden Betrachtungen, welche die Kraft der Körper überhaupt betreffen (AK 1: 1-181); English translation by M. Schönfeld (in press) Thoughts on the true estimation of living forces, in E. Watkins (ed.) Natural Science, The Cambridge edition of the works of Immanuel Kant (Cambridge: Cambridge University Press).

(1754) Untersuchung der Frage, ob die Erde in ihren Umdrehung um die Achse...einige Veränderung seit den ersten Zeiten ihres Ursprungs erlitten habe (AK I: 183-91). Engl. translation (1968) "Whether the earth has undergone an alteration of its axial rotation", in W. Ley (ed.) Kant's Cosmogony (New York: Greenwood Publishing).

(1755a) Allgemeine Naturgeschichte und Theorie des Himmels oder Versuch von der Verfassung und dem mechanischen Ursprunge des ganzen Weltgebäudes, nach Newtonischen Grundsätzen abgehandelt (AK 1: 215-368). Engl. translation (1968) Universal Natural History and Theory of the Heavens, in W. Ley (ed.) Kant's Cosmogony (New York: Greenwood Publishing).

(1755b) Meditationum quarundam de igne succincta delineatio (AK 1: 36984). Engl. translation Succinct exposition of some meditations on fire, in L. W. Beck et al. (1986) Kant's Latin Writings (New York: Peter Lang).

(1755c) Principiorum primorum cognitionis metaphysicae nova dilucidatio (AK 1: 385-416). Engl. translation New elucidation, in D. Walford and R. Meerbote (eds.) (1992) Theoretical Philosophy 1755-1770. The Cambridge edition of the works of Immanuel Kant (Cambridge: Cambridge University Press).

(1756) Metaphysicae cum geometria iunctae usus in philosophia naturali, cuius specimen I. continet monadologiam physicam (AK 1: 473-87). Engl. translation 
Physical Monadolody, in D. Walford and R. Meerbote (eds.) (1992) Theoretical Philosophy 1755-1770. The Cambridge edition of the works of Immanuel Kant (Cambridge: Cambridge University Press).

(1786) Metaphysische Anfangsgründe der Naturwissenschaft (Riga: Johann Hartknoch). Engl. translation (2004) by M. Friedman, Metaphysical Foundations of Natural Science (Cambridge: Cambridge University Press).

(1936, 1938) Opus postumum. In Kants gesammelte Schriften (Berlin: de Gruyter); Ak 21, 22. English translation (1993) Opus postumum, by Eckart Förster and Michael Rosen, The Cambridge Edition of the Works of Immanuel Kant (Cambridge: Cambridge University Press).

Keill, John (1720) An Introduction to Natural Philosophy; or, Philosophical Lectures read in the University of Oxford, Anno Dom. 1700 (London: William and John Innys and John Osborne).

Kerker, M. (1955) "Herman Boerhaave and the development of pneumatic chemistry", Isis 46, pp. 36-49.

Kuehn, M. (2001) "Kant's teachers in the exact sciences", in E. Watkins (ed.) Kant and the Sciences (Oxford: Oxford University Press).

Laywine, A. (1993) Kant's early metaphysics and the origins of the critical philosophy (Atascadero: Ridgeview Publishing Company).

Leibniz, G. W. (1695) Specimen dynamicum pro admirandis naturae legibus circa corporum vires et mutuas actiones detegendis, et ad suas causas revocandis, in Acta Eruditorum, pp. 145-157. Engl. translation Specimen dynamicum, in L. E. Loemker (ed.) (1969) Gottfried Wilhelm Leibniz: Philosophical Papers and Letters: A Selection (Riedel: Dordrecht), pp. 435-452. (1689) “Tentamen de motuum coelestium causis", Acta eruditorum, p. 82. English translation in D. Bertoloni Meli (1993), Equivalence and Priority: Newton versus Leibniz (Oxford: Clarendon Press), pp. 126-42.

de Maupertuis, P. L. M. (1732) Discours sur les différentes figures des asters (Paris). Metzger, H. (1930) Newton, Stahl, Boerhaave et la doctrine chimique, (Paris: F. Alcan).

Musschenbroek, P. (1734) Elementa Physicae, conscripta in usus Academicos (S. Luchtmans. Lugduni Batavorum). English translation by John Colson (1744) The Elements of Natural Philosophy. Chiefly intended for the use of students in Universities (London: J. Nourse), 2 vols. 
Newton, Sir I. (1674) "De aere et aethere" in A. R. Hall and M. B. Hall (1962) Unpublished scientific papers of Isaac Newton (New York: Cambridge University Press), pp. 214-228. (1687/1713) Philosophiae Naturalis Principia Mathematica (London: Joseph Streator). English translation (1729) by A. Motte The Mathematical Principles of Natural Philosophy (London: Benjamin Motte). Translation revised by Florian Cajori (1934), (Berkeley: University of California Press).

(1704/1717) Opticks: or, A Treatise of the Reflections, Refractions, Inflections and Colours of Light (London: W. and J. Innys), 2nd edition, with additions. Edition used (1952) based on the fourth ed., London 1730, with a Preface by I. Bernard Cohen.

Pozzo, R. and Oberhausen, M. (2002) "The place of science in Kant's university”, History of Science 40, pp. 353-368.

Ruestow, E. G. (1973) Physics at seventeenth and eighteenth-century Leiden: Philosophy and the New Science in the University (Kluwer).

Schofield, R. E. (1970) Mechanism and materialism. British Natural Philosophy in an Age of Reason (Princeton: Princeton University Press).

Schönfeld, M. (2000) The Philosophy of the Young Kant (New York: Oxford University Press). (2006a) "Kant's early dynamics" in G. Bird (ed.) A Companion to Kant, (Blackwell Publishing), pp. 33-46.

(2006b) "Kant's early cosmology" G. Bird (ed.) A Companion to Kant, (Blackwell Publishing), pp. 47-62.

Warda, A. (1922) Immanuel Kants Bücher. Mit einer getreuen Nachbildung des bisher einzigen bekannten Abzuges des Versteigerungskataloges der Bibliothek Kants (Berlin: Breslauer).

Watkins, E. (2001) Kant and the Sciences (Oxford: Oxford University Press). (2005) Kant and the Metaphysics of Causality (Oxford: Oxford University Press).

Westfall, R. S. (1971) Force in Newton's Physics. The science of dynamics in the seventeenth century (MacDonald: London). 
